\title{
Vendor Comparison of Video Detection Systems
}

\author{
By \\ Avery Rhodes, EIT \\ Graduate Research Assistant \\ Edward J. Smaglik, Ph.D. \\ Post Doctoral Research Associate, \\ and \\ Darcy Bullock, Ph.D., PE \\ Professor of Civil Engineering
}
School of Civil Engineering
Purdue University
Joint Transportation Research Program
Project Number: C-36-17QQQ
File Number: 8-4-69
SPR-2869

Prepared in Cooperation with the

Indiana Department of Transportation and the

U. S. Department of Transportation

Federal Highway Administration

The contents of this report reflect the views of the authors, who are responsible for the facts and the accuracy of the data presented herein. The contents do not necessarily reflect the official views and policies of the Indiana Department of Transportation or Federal Highway Administration at the time of publication. The report does not constitute a standard, specification or regulation.

\author{
Purdue University \\ West Lafayette, IN 47907 \\ May 2006
}




\section{TECHNICAL Summary}

INDOT Research

Technology Transfer and Project Implementation Information

TRB Subject Code: 54-5 Traffic Control Devices

Publication No.FHWA/IN/JTRP-2005/30, SPR-2869

May 2006

Final Report

\section{Vendor Comparison of Video Detection Systems}

\section{Introduction}

Video detection has become a popular replacement for traditional loop detectors at signalized intersections. While loop detectors are a relatively mature device, the experience with video detection is much more limited. The Indiana Department of Transportation suspended the deployment of video detection subsequent to a 2001 JTRP report detailing several problems with the technology. These included missed calls at night at intersections with limited lighting and the tendency for video detectors to extend detection zones significantly at night due to headlight reflection off of the pavement.

In 2002, suggestions to improve the performance of video detection were posed by video detection manufacturers. They were primarily concerned with

the placement of cameras, and suggested a preferred lateral offset and camera height.
In late 2003 and the summer of 2004, two test beds were constructed at signalized intersections in Noblesville, Indiana and West Lafayette, Indiana respectively. A camera was located at the vendor preferred location and several other cameras were located at slightly less optimal locations.

This report details the procedures used to evaluate three separate video detection systems at one of the test sites with respect to missed presence calls and false presence calls. A procedure to evaluate the consistency of detection zones between day and night lighting conditions is also presented. The conclusions of this report provide the Indiana Department of Transportation with important considerations when choosing detection technology at signalized intersections.

\section{Findings}

Autoscope (version 8.10), Peek UniTrak (version 2), and Iteris Vantage (Camera CAM-RZ3) were evaluated on the same traffic conditions at the Noblesville test site. All video detection systems were observed to fail to detect a large number of vehicles. Such performance is unacceptable and justifies INDOT's moratorium on video detection at signalized intersections. Furthermore, the high number of false calls is unacceptable due to the resulting motorist delay.

\section{Implementation}

This report provides a comprehensive evaluation of the Autoscope (version 8.10), Peek UniTrak (version 2), and Iteris Vantage (Camera CAMRZ3) stop bar video detection systems at signalized intersections. The deployment of video detections systems at signalized intersections is not recommended due to the following:
- Each video detection system showed a moderate to high number of missed and false calls over the two test periods.

- The loop detector showed only one missed call and 1 false call over both 48 hour test periods. The missed call was due to a wild vehicle path, while the false call was due to an unexplained eightsecond extension. 
- None of the three systems appeared to provide superior performance over the other three. The most accurate and reliable technology was the traditional loop detectors.
- The accuracy of all three systems appears to degrade with time and it appeared that a re-calibration was necessary only four months after the initial installation by factory representatives.

\section{Contacts}

For more information:

Prof. Darcy Bullock

Principal Investigator

School of Civil Engineering

Purdue University

West Lafayette IN 47907

Phone: (765) 494-2226

Fax: (765) 496-7996

E-mail: darcy@purdue.edu
Indiana Department of Transportation

Division of Research

1205 Montgomery Street

P.O. Box 2279

West Lafayette, IN 47906

Phone: (765) 463-1521

Fax: (765) 497-1665

\section{Purdue University}

Joint Transportation Research Program

School of Civil Engineering

West Lafayette, IN 47907-1284

Phone: (765) 494-9310

Fax: (765) 496-7996

E-mail: jtrp@ecn.purdue.edu

http://www.purdue.edu/jtrp 
This is a three-volume report; links to remaining two volumes are included in each volume.

TECHNICAL REPORT STANDARD TITLE PAGE

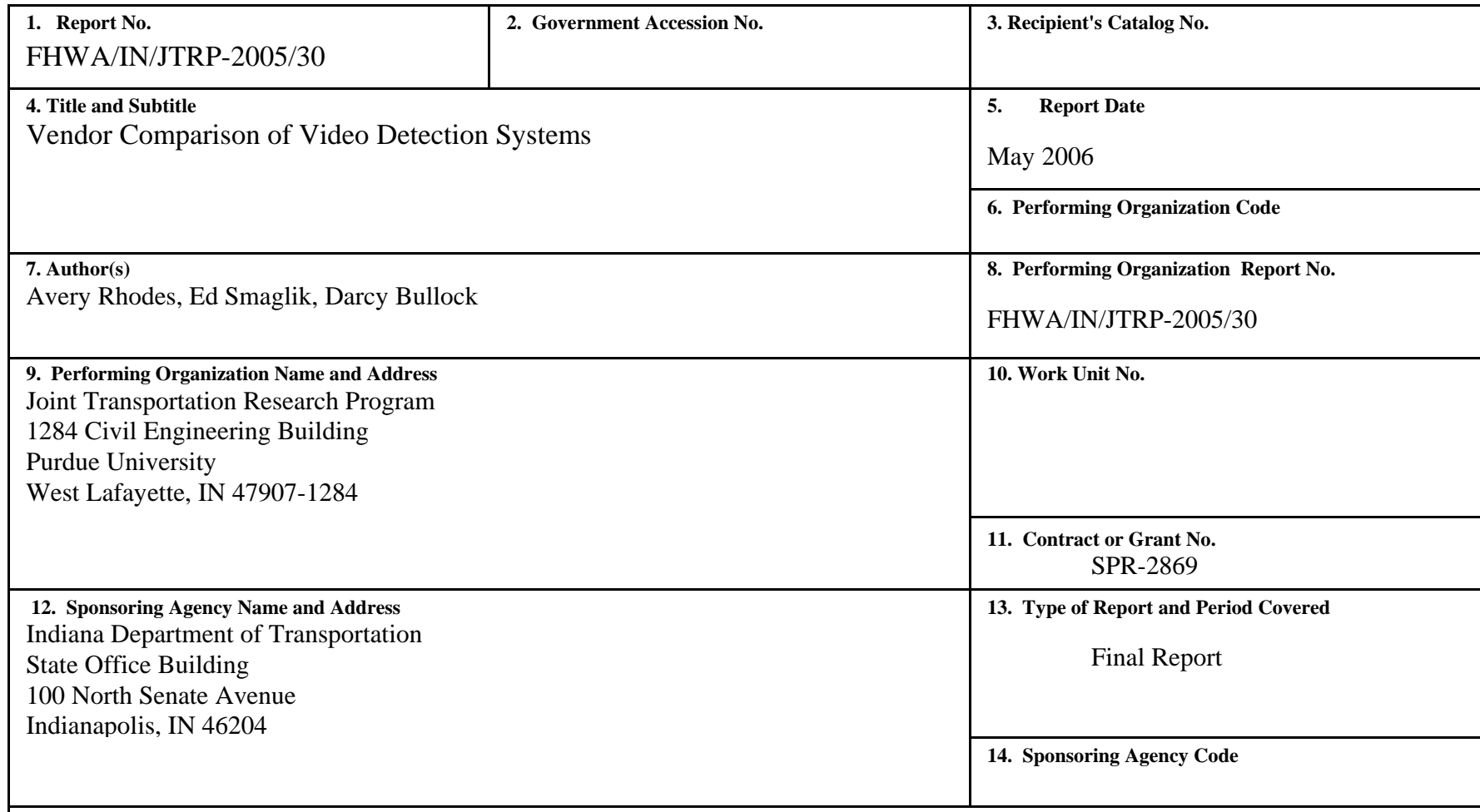

15. Supplementary Notes

Prepared in cooperation with the Indiana Department of Transportation and Federal Highway Administration.

16. Abstract

Video detection has become increasingly popular for presence detection at signalized intersections because of its versatility. However, several reports have documented performance problems in specific systems. This paper quantifies the performance of three different commercially available video detection systems. The systems were tested in May and September 2005 for presence detection accuracy.

Prior to the May 2005 test, a representative from each vendor configured the video detection zones to match the loop detection zone as closely as possible. The outputs from the loop detection for the through-right and left-turn lane groups were compared with the corresponding output from each of the video detection systems. Whenever there was a discrepancy between the loop and video, a digital video was observed to determine the cause of the discrepancy.

Missed calls and false calls were categorized for each system. The errors were also categorized according to the impact that they would have on signal operations. During a $24 \mathrm{hr}$ test on two separate days, the number of missed detections longer than 5 seconds ranged from 9 to 147, and the number of false calls longer than 5 seconds ranged from 16 to 149 .

17. Key Words

Traffic engineering, traffic signals, traffic surveillance, traffic management, traffic control devices, loops, intelligent transportation systems, video detection, vehicle detector performance
18. Distribution Statement

No restrictions. This document is available to the public through the National Technical Information Service, Springfield, VA 22161

\begin{tabular}{|c|c|c|c|}
\hline $\begin{array}{c}\text { 19. Security Classif. (of this report) } \\
\text { Unclassified }\end{array}$ & $\begin{array}{c}\text { 20. Security Classif. (of this page) } \\
\text { Unclassified }\end{array}$ & 22. Price & 41 \\
\hline
\end{tabular}




\section{INTRODUCTION}

Video detection has become a popular replacement for traditional loop detectors at signalized intersections. While loop detectors are a relatively mature device, the experience with video detection is much more limited. The Indiana Department of Transportation suspended the deployment of video detection subsequent to a 2001 JTRP report detailing several problems with the technology. These included missed calls at night at intersections with limited lighting and the tendency for video detectors to extend detection zones significantly at night due to headlight reflection off of the pavement.

In 2002, suggestions to improve the performance of video detection were posed by video detection manufacturers. They were primarily concerned with the placement of cameras, and suggested a preferred lateral offset and camera height.

In late 2003 and the summer of 2004, two test beds were constructed at signalized intersections in Noblesville, Indiana and West Lafayette, Indiana respectively. A camera was located at the vendor preferred location and several other cameras were located at slightly less optimal locations.

This report details the procedures used to evaluate three separate video detection systems at one of the test sites with respect to missed presence calls and false presence calls. A procedure to evaluate the consistency of detection zones between day and night lighting conditions is also presented. The conclusions of this report provide the Indiana Department of Transportation with important considerations when choosing detection technology at signalized intersections. 


\section{FINDINGS}

Autoscope (version 8.10), Peek UniTrak (version 2), and Iteris Vantage (Camera CAMRZ3) were evaluated on the same traffic conditions at the Noblesville test site. All video detection systems were observed to fail to detect a large number of vehicles. Such performance is unacceptable and justifies INDOT's moratorium on video detection at signalized intersections. Furthermore, the high number of false calls is unacceptable due to the resulting motorist delay. 
TABLE OF CONTENTS

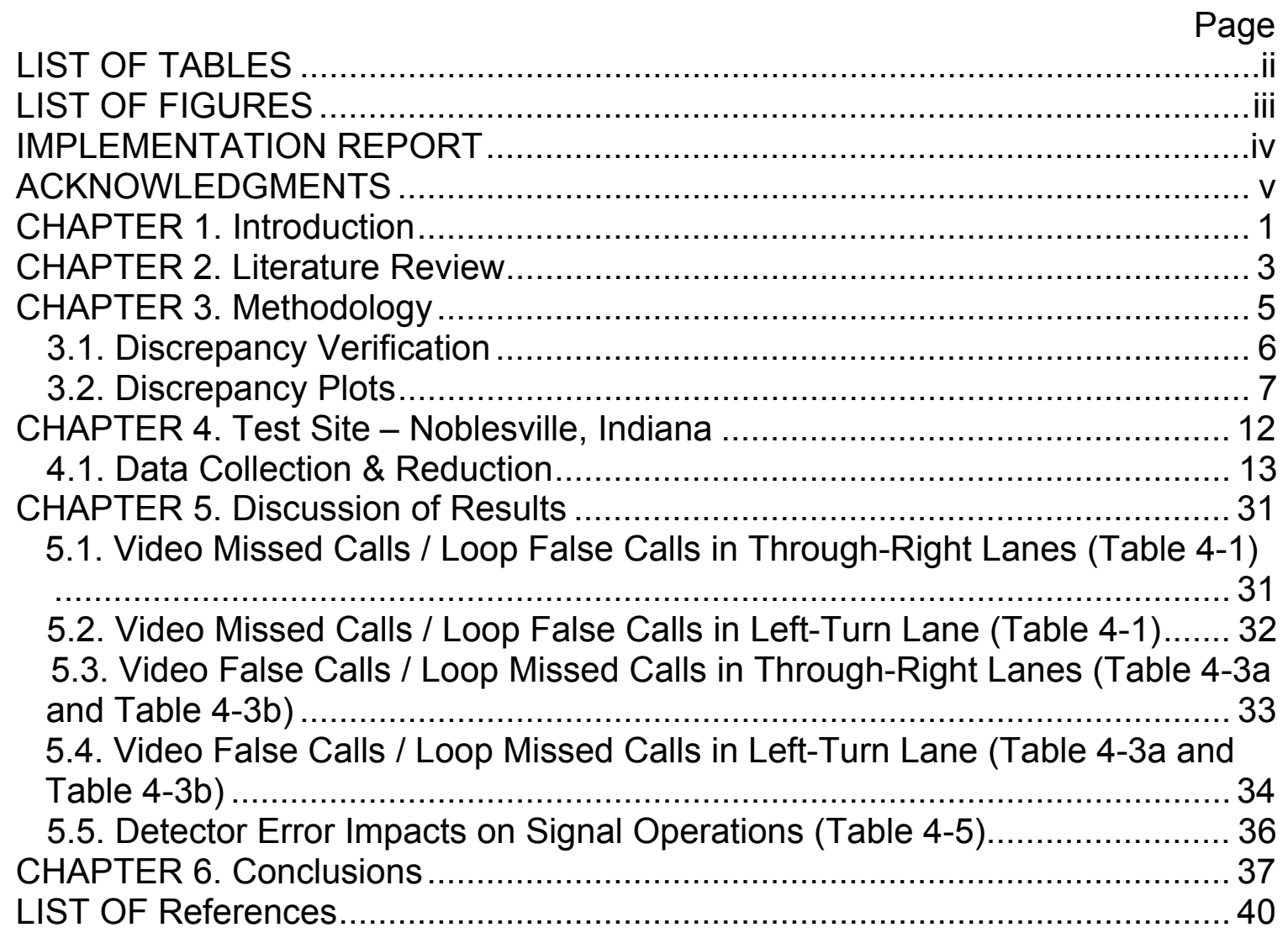


LIST OF TABLES

Table

Page

Table 4-1: Tabulation of Missed Calls Longer than 5 seconds .........................2 25

Table 4-2: Missed Call Error Classification Code .......................................... 26

Table 4-3: Tabulation of False Calls Longer than 5 seconds .......................... 27

Table 4-4: False \& Latched Call Error Classification Code ............................... 28

Table 4-5: Tabulation of Detector Error Impacts on Signal Operations .............. 29

Table 4-6: Phase Actuation Error Descriptions.................................................. 30 


\section{LIST OF FIGURES}

Figure

Page

Figure 3-1: LOV1 and L1V0 Discrepancy Concept.................................. 9

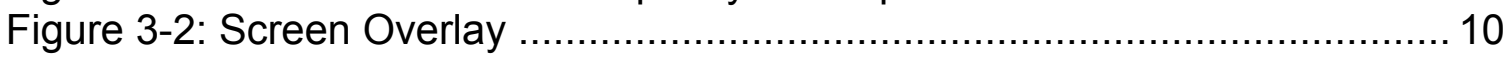

Figure 3-3: Example L1V0 / LOV1 Graphs ......................................... 10

Figure 3-4: Example Histograms of Video Detection Timing Errors.................. 11

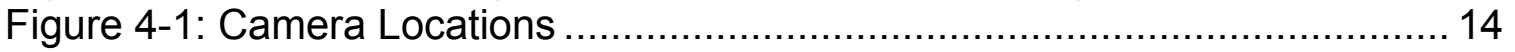

Figure 4-2: Views from Camera with Detection Zones ................................ 15

Figure 4-3: L1V0 and L0V1 Graphs for Through-Right Movement, May 2 ${ }^{\text {nd }}, 2005$

Figure 4-4: L1V0 and LOV1 Graphs for Left-Turn Movement, May $2^{\text {nd }}, 2005 \ldots 17$

Figure 4-5: Activation and Deactivation Histograms for Through Movement, May $2^{\text {nd }}, 2005$

Figure 4-6: L1V0 and L0V1 Graphs for Through-Right Movement, September $21^{\text {st }}, 2005$

Figure 4-7: L1V0 and L0V1 Graphs for Left-Turn Movement, September $21^{\text {st }}$, 2005

Figure 4-8: Activation and Deactivation Histograms for Through Movement, September $21^{\text {st }}, 2005$

Figure 4-9: Example Autoscope Errors.................................................. 22

Figure 4-10: Example Peek Errors ....................................................... 23

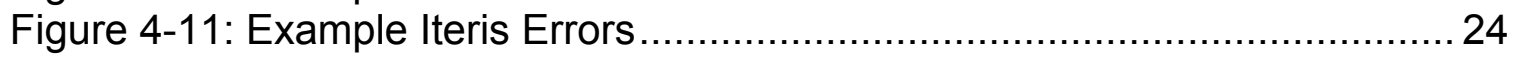




\section{IMPLEMENTATION REPORT}

This report provides a comprehensive evaluation of the Autoscope (version 8.10), Peek UniTrak (version 2), and Iteris Vantage (Camera CAM-RZ3) stop bar video detection systems at signalized intersections. The deployment of video detections systems at signalized intersections is not recommended due to the following:

- Each video detection system showed a moderate to high number of missed and false calls over the two test periods.

- The loop detector showed only 1 missed call and 1 false call over both 48 hour test periods. The missed call was due to a wild vehicle path, while the false call was due to an unexplained 8 second extension.

- None of the three systems appeared to provide superior performance over the other three. The most accurate and reliable technology was the traditional loop detectors.

- The accuracy of all three systems appears to degrade with time and it appeared that a re-calibration was necessary only 4 months after the initial installation by factory representatives. 


\section{ACKNOWLEDGMENTS}

This work was supported by the Joint Transportation Research Program administered by the Indiana Department of Transportation and Purdue University. The support for installing and configuring the video detection devices was provided by respective personnel for Econolite, Iteris, and Peek. The contents of this paper reflect the views of the authors, who are responsible for the facts and the accuracy of the data presented herein, and do not necessarily reflect the official views or policies of the Federal Highway Administration and the Indiana Department of Transportation, nor do the contents constitute a standard, specification, or regulation. 


\section{CHAPTER 1. INTRODUCTION}

The majority of traffic signals operate by responding to traffic demands at the intersection. The controller receives its' information through vehicle detectors installed in or above the pavement. The most commonly used detection technology are inductive loops, which are copper wires installed in a circular loop shape into the pavement.

While loops generally provide very accurate detection, they have several shortcomings that have led agencies to explore alternative forms of vehicle detection. The main disadvantages of loops are related to the fact that the technology is an intrusive form of detection; that is, the loops are installed directly into the pavement. This is problematic for several reasons, including the fact that installation necessitates the closure of traffic lanes, installation in the pavement may cause damage to the pavement structure, and installation may not be feasible on intersection approaches constructed on bridge decks or with decorative pavement such as a brick roadway. Additionally, since the loop detectors are installed into the roadway surface they are prone to damage due to construction on the roadway or from failing and cracking pavement.

Several non-intrusive detection devices have been introduced over the past few decades that could potentially eliminate the disadvantages that intrusive detection devices have. Also, since these devices are installed above the pavement, they offer more flexibility in adjusting detection zones, which can be helpful during special events or construction restrictions where lane configurations may be temporarily changed.

Non-intrusive detection devices have employed a variety of technologies to detect moving and stationary vehicles, including microwave (radar), acoustic, and video. Video detection is the most widely deployed non-intrusive detection at 
signalized intersections. Video detection uses the images from a video camera to detect vehicles within pre-defined detection zones by processing the images using computer algorithms.

Video detection has become popular for its flexibility. For example detection zones can easily be manipulated and configured as needed. Some agencies may find the video images valuable to bring back to a central office location or a Traffic Management Center (TMC). At some locations where a bucket truck can safely park outside of the traveled way it may be possible to service and/or replace video detection units without closing the roadway.

Despite these advantages of video detection, the technology has been scrutinized more recently as to how well it performs as a stop bar presence detector at signalized intersections. Several studies have been completed in recent years comparing the operational accuracy of video detection to competing technologies such as traditional inductive loops. The research is remarkably consistent in identifying many operational disadvantages inherent in video detection.

A recent article in the Washington Post (1) highlights some of the problems with video detection and the dramatic effect that inaccurate detection can pose to operations. Ultimately the purpose of a vehicle detector is to provide accurate detection to operate a transportation system in the most effective manner possible. While video detection provides some conveniences for the transportation official, the detector must ultimately prove itself beneficial to the motoring public. 


\section{CHAPTER 2. LITERATURE REVIEW}

Perhaps the earliest evaluation of video detection was published by MacCarley et. al. in 1992 (2) which compared the performance of 8 video detection systems. In this research, several 20-minute test video clips were created so each system could be tested with the same traffic, lighting and weather conditions. While improvements to the technology have undoubtedly occurred since 1992, MacCarley et. al. cite many of the same problems with the technology that are mentioned in more recent research, namely inaccurate detection during transitional lighting periods and poor weather conditions such as rain.

Another research project conducted in the mid-1990's in a joint effort between the Minnesota Department of Transportation (MnDOT) and the Federal Highway Administration (FHWA) also compared competing video detection systems (3). In these tests the Econolite Autoscope 2004 and Peek Video Trak900 video detection systems were compared. The test sites included freeway locations as well as an signalized intersection application. While results from the freeway test location were favorable under optimal conditions, the performance of the detectors at the intersection test site were much more inconsistent. The researchers documented the degradation in performance under non-ideal conditions including the transitional periods at sunrise and sunset where stationary and moving shadows, and direct sunlight compromised the accurate performance of the detectors. The two competing products were reported to demonstrate comparable performance.

In 2002, Middleton et. al. (4) completed an evaluation of alternative vehicle detectors in a freeway setting. Among the detectors tested were the Econolite Autoscope Solo Pro and Iteris Vantage. The Autoscope camera was mounted 7 
feet higher than the Iteris Vantage and therefore a direct comparison of the performance of the two systems is probably inappropriate. However, if the difference in mounting height was considered negligible, the Iteris Vantage did perform better than the Autoscope during congested traffic conditions, but overall had a higher standard deviation for vehicle counts. The report indicated that both the Autoscope and Iteris systems demonstrated good and consistent occupancy values.

In 2001, Grenard et. al (5) developed a methodology for evaluating detectors for how well they served as presence detectors. This methodology was utilized further in 2005 by Rhodes et. al (6) to test the Autoscope Solo Pro and is again used in this paper to compare three competing video detection systems. This research also relies and expands on several vehicle detection event classes by applying the protocal defined by MacCarley and Palen (7) to more consistently describe the types of detection errors that were observed during this test. These authors also defined several phase actuation events that describe the effect that the incorrect detection will have on signal operations. 


\section{CHAPTER 3. METHODOLOGY}

The methodology used in this paper to evaluate video detection is focused on the accuracy of presence detection, using best practices adopted from Grenard et al (5), Rhodes et al (6), and MacCarley and Palen (7). While speed and volume are easily quantifiable metrics, they do not necessarily portray how well a detector is going to operate at a signalized intersection.

To identify potential errors such as missed calls or false calls, the output from each of the video detectors is compared to the output of a loop detector. The video detectors were each configured by vendor representatives to replicate the loop detector zones as closely as possible.

Discrepancies between the two types of detection technologies were identified by comparing the output from each and determining when the detector states were not in agreement. An example of identifying discrepancies is displayed in Figure 3-1a. In this graph, initially both the video detector and loop detector are not active. At time $\mathrm{t}=2.5 \mathrm{~s}$, both the loop and the video detector activate, however at time $t=5.0 \mathrm{~s}$, the video deactivates while the loop remains active, therefore a discrepancy is identified where the loop indicates a presence while the video does not indicate a presence. This type of discrepancy is labeled as a L1V0 event as shown at the bottom of Figure 3-1a. Similarly, between $t=8.0 \mathrm{~s}$ and $\mathrm{t}=10.0 \mathrm{~s}$, a discrepancy (with a duration of 2.0s) occurs where the loop indicates there is no vehicle presence, while the video detector indicates that a vehicle is present. This type of event is categorized as a LOV1 event.

LOV1 and L1V0 events follow a rather simple syntax. The 'L' stands for loop while the ' $V$ ' stands for video detection, the number following each letter 
indicates whether the identified detector is indicating a presence (1) or indicating that there is no vehicle present $(0)$.

L1V0 and LOV1 events are not termed as errors because although a discrepancy has been identified between the two detectors, it is not known which detector was in error until human observation of the event takes place. It is also possible that detector errors could occur but not be identified by the L1V0 and LOV1 discrepancy events. For example, it might be possible that both the loop detector and video detector are in error at the same exact moment and therefore a discrepancy between the two detectors is not identified. Although this is a limitation to the procedure, such a circumstance would be rather unlikely.

In Figure 3-1b, the possible event states are shown in each row. The possible errors that would cause a discrepancy are also shown in Figure 3-1b. It is possible that a discrepancy event could either be caused by the loop detector or by the video detector. For example, an LOV1 discrepancy event could have been caused by a missed detection by the loop detector or a false detection by the video detector.

The consequences of detector errors during presence detection at a signalized intersection are twofold, safety and efficiency. False detection calls can potentially degrade the performance of a signalized intersection because the controller will allocate capacity to vehicles that are not actually present. Conversely, safety impacts occur when the vehicle detector misses legitimate calls. For example, a vehicle that is not served by the signal controller because the vehicle detector has not reported its presence may grow impatient and violate a red signal. The impact due to loop or video detection errors under the various event states are tabulated in the last column of Figure $3-1 b$.

\subsection{Discrepancy Verification}

To determine the cause of each discrepancy, a digital video of the intersection approach was captured during the test period. The digital video includes a screen overlay that provides the status of several important 
parameters such as video detector states, loop detector state, date and time, and signal state. The screen overlay is shown in Figure 3-2. The digital video allows an observer to visually verify discrepancies and to categorize them as being an error by the loop detector or the video detector. Items 1 through 4 correspond to the state of the through-right lane group detectors. Item 1 refers to the loop detector state, while items 2 through 4 refer to the video detector states and are labeled by brand name in the overlay. Items 6 through 9 refer to the detector states in the left-turn lane group. In the screen overlay shown in Figure 3-2, the through-lane detectors are active as represented by the thick black text while the left-turn lane detectors are inactive as indicated by the hollow white text. The detector states shown on the screen overlay in Figure 3-2 are as expected since a vehicle is present in the through lane while no vehicles are present in the leftturn lanes.

The signal states are also shown in this video overlay and are indicated by items 5 and 10 for the through and left-turn phases, respectively. In this overlay, the through phase is green while the left-turn phase is red. At this location protected-permissive phasing is used for the left-turn phases, so in this case the left-turn phase is permitted when the through is shown as green and the left-turn is shown as red.

Other information included in the screen overlay shown in Figure 3-2 includes the date and time (Item 11), a title (Item 12), and phase number labels (Items 13 and 14).

\subsection{Discrepancy Plots}

Two methods have been developed to compare the performance of loop detectors and video detectors visually. The first method simply plots the duration of discrepancies between loops and video versus time of day. Two graphs are developed for each video detector per test period, one for LOV1 discrepancies and the other for L1V0 discrepancies. While the graph gives a quick visual indicator on the number and magnitude of discrepancies between two detection 
technologies, it cannot be concluded from the graph alone which detector is performing better until a separate visual ground truth process occurs. Example L0V1 and L1V0 graphs are shown in Figure 3-3.

The second visual method used to compare the performance of loop detectors and video detectors are on-time and off-time histograms. Example activation and deactivation histograms are shown in Figure 3-4. The 0.0s time at the middle of each histogram is the time corresponding to the activation or deactivation of the inductive loop. Since loop detectors behave very consistent over a wide range of weather and lighting conditions they were used as the baseline for on-times and off-times. On the other hand, video detectors rely on visual cues that may change in different ambient lighting conditions; such as headlights activating the detector earlier at night than the vehicle would during the day. Similarly, vehicle height may cause changes in the video detector turnoff time as taller vehicles will visually remain in the detection zone longer than shorter vehicles.

The primary use of these on and off-time histograms is to document any changes in detector performance between day and night periods. 


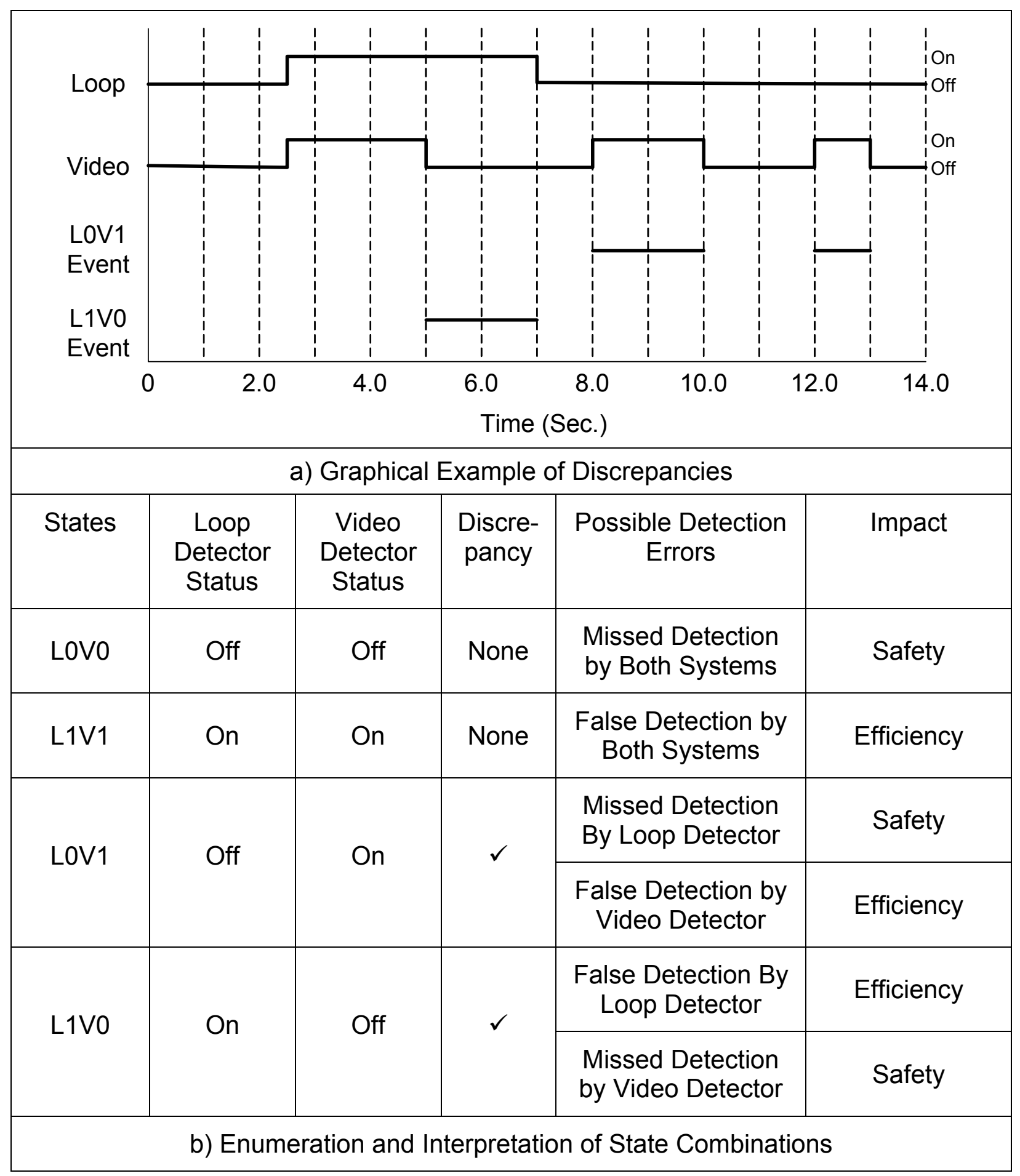

Figure 3-1: LOV1 and L1V0 Discrepancy Concept. 


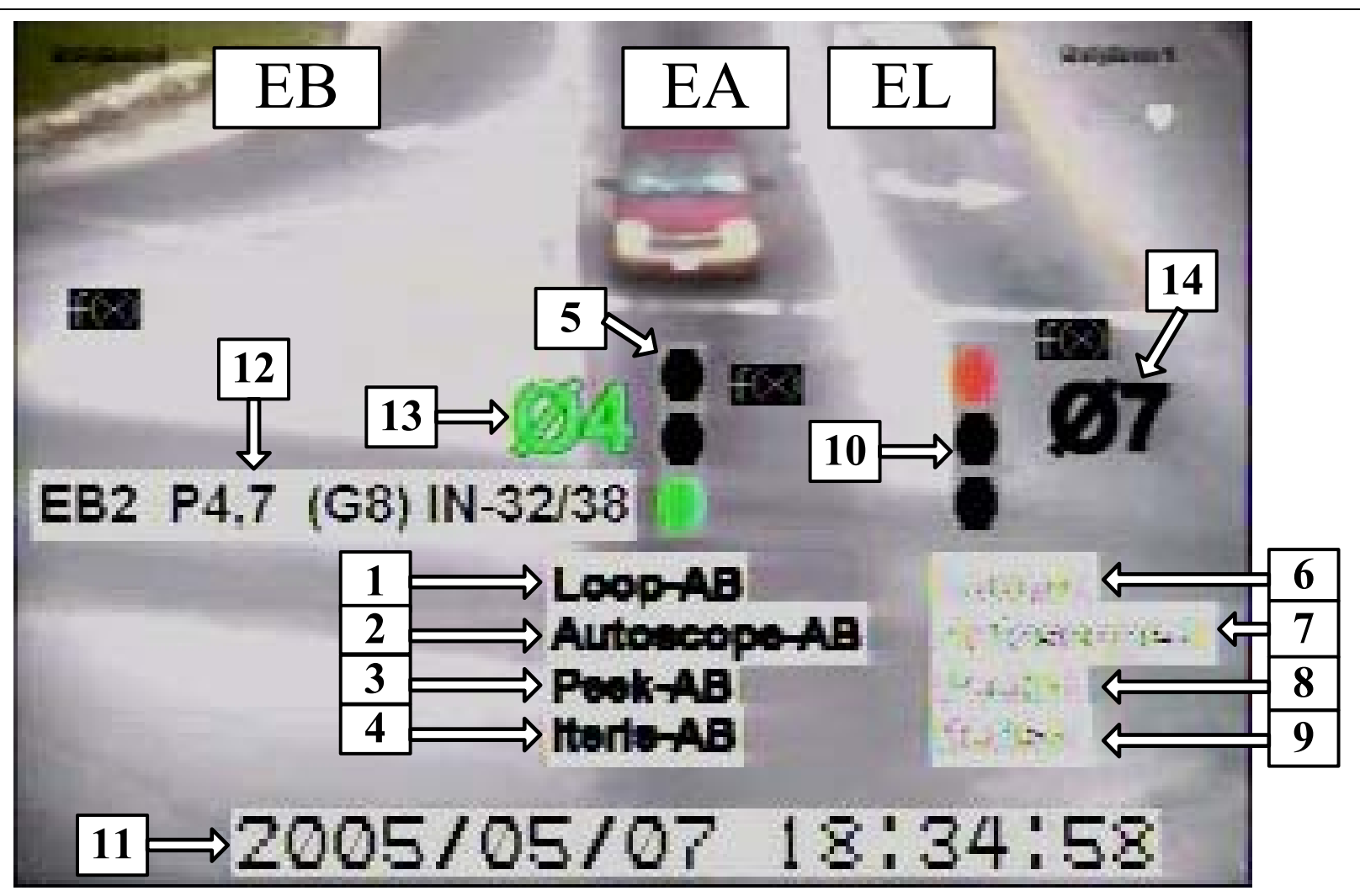

Figure 3-2: Screen Overlay

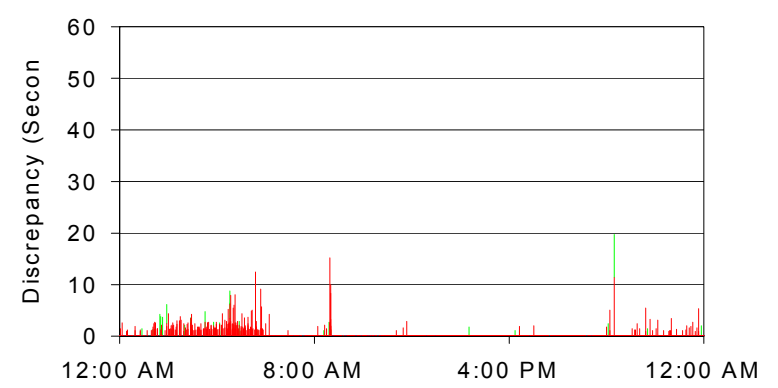

a) L1V0

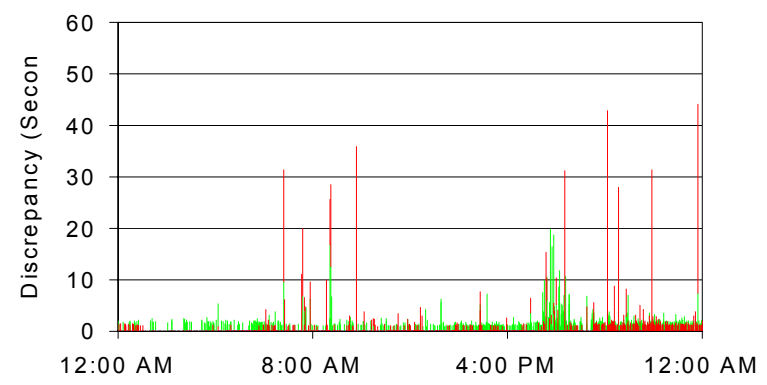

b) LOV1

Figure 3-3: Example L1V0 / LOV1 Graphs 
Time Difference between Loop Detector and Video Detector Activation (Seconds)

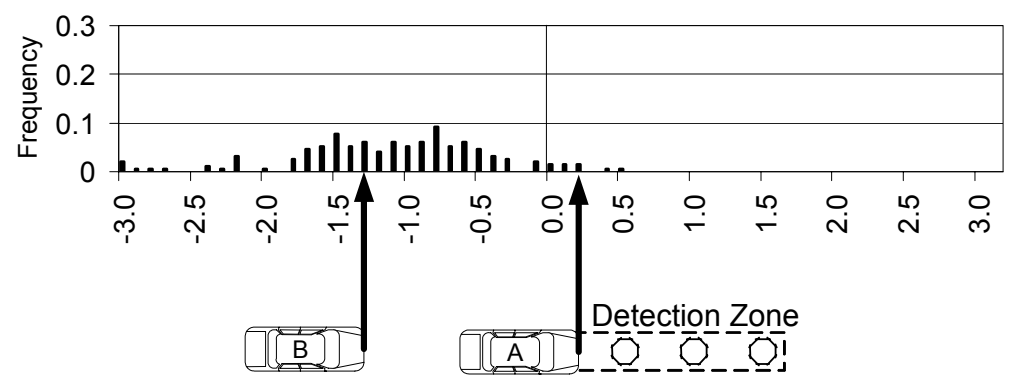

b) Example Activation Histogram

Time Difference between Loop Detector and Video Detector Deactivation (Seconds)

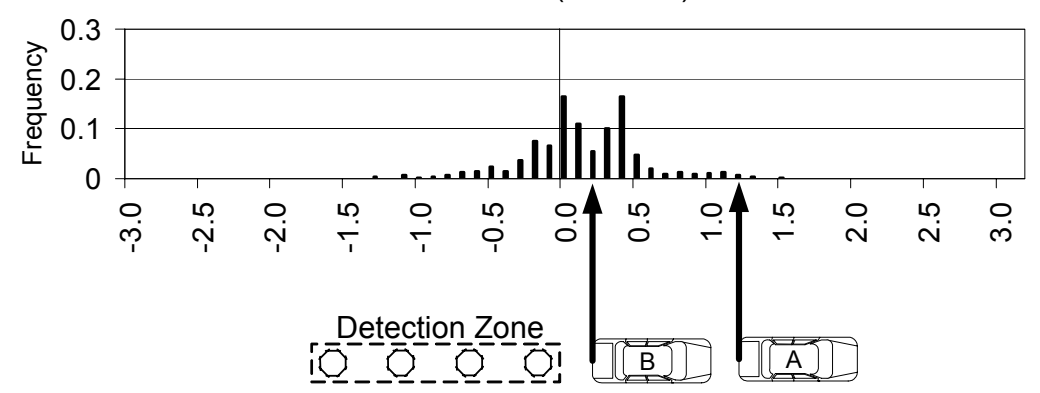

c) Example Deactivation Histogram

Figure 3-4: Example Histograms of Video Detection Timing Errors 


\section{CHAPTER 4. TEST SITE - NOBLESVILLE, INDIANA}

A test site was constructed in Noblesville, Indiana during Summer 2003. Each approach was instrumented with stop bar loop detectors and Econolite Autoscope video detection. In Early 2005, Peek Unitrak and an Iteris Vantage video detection was added to the Westbound leg of the intersection, detecting Eastbound traffic. The cameras were installed at a height of 40 feet and a lateral distance of 48' out on the mast arm. A photograph of the installation is shown in Figure 4-1.

A representative of each manufacturer visited the intersection to install, configure and fine-tune the video detectors. A screen shot from each of the three tested manufacturers is shown in Figure 4-2. Each vendor was shown the existing loop detection zones and instructed to match the detection zones as closely as possible during the video detection setup. The video detection zones as setup by each vendor is shown on the screen shots of Figure 4-2. It should be noted that each manufacturer displays the detection zones on screen differently. In Figure 4-2a, the Autoscope detection zone is represented by narrow bars in each lane with an arrow indicating the direction of flow. In Figure 4-2b, the Peek detection zones are represented by rectangles with arrows in the center representing the direction of flow. In Figure 4-2c, the Iteris detection zones are outlined with small white marks at the corner of each zone.

In early September 2005, Peek installed an infrared unit to work in concert with the visual camera in its detection system. The Iteris and Autoscope systems remained unchanged. 


\subsection{Data Collection \& Reduction}

Data collection occurred on May 2, 2005 and September 21, 2005. Detector states and phase states were recorded in a text file. The video with screen overlay was collected in a digital video file to verify and ground truth the data. Using Microsoft Access and Excel, the text file is employed to generate the LOV1 graph, LOV1 graph, and on-time and off-time histograms (Figure 4-3, Figure 4-4, and Figure 4-5 for the May test, and Figure 4-6, Figure 4-7, and Figure 4-8 for the September test). Example discrepancies from the May test are highlighted from Figure 4-3 and Figure 4-4 using Figure 4-9, Figure 4-10, and Figure 4-11. For example, the notation 'AS-E1' appears in Figure 4-3a, corresponding to an individual Autoscope discrepancy. The cause of this discrepancy is shown in Figure 4-9a and Figure 4-9b. The same method is used to highlight example discrepancies from the Peek and Iteris cameras using Figure 4-10 and Figure 4-11 respectively. In addition, a list of each video / loop discrepancy greater than 5 seconds on each of the three cameras was generated. These discrepancies were compared with the archived video to determine the cause (video or loop).

Once discrepancies were confirmed to be errors, each error was classified based upon the cause of the error. The summary of discrepancies found to be missed calls is shown in Table 4-1. Full descriptions of the different classifications are shown in Table 4-2. The summary of discrepancies classified to be false calls is shown in Table 4-3a. Full descriptions of the different classification are shown in Table 4-4. In addition, false calls that latched were tabulated. False latched calls are a subset of the total amount of false calls, characterized by the video detector remaining on after the stimulus that originally activated the video detection zone is removed. A summary of these is detailed in Table 4-3b. Finally, the impact that each missed call and false call would have on phase actuation was classified in Table 4-5. Description of this classification is shown in Table 4-6. 


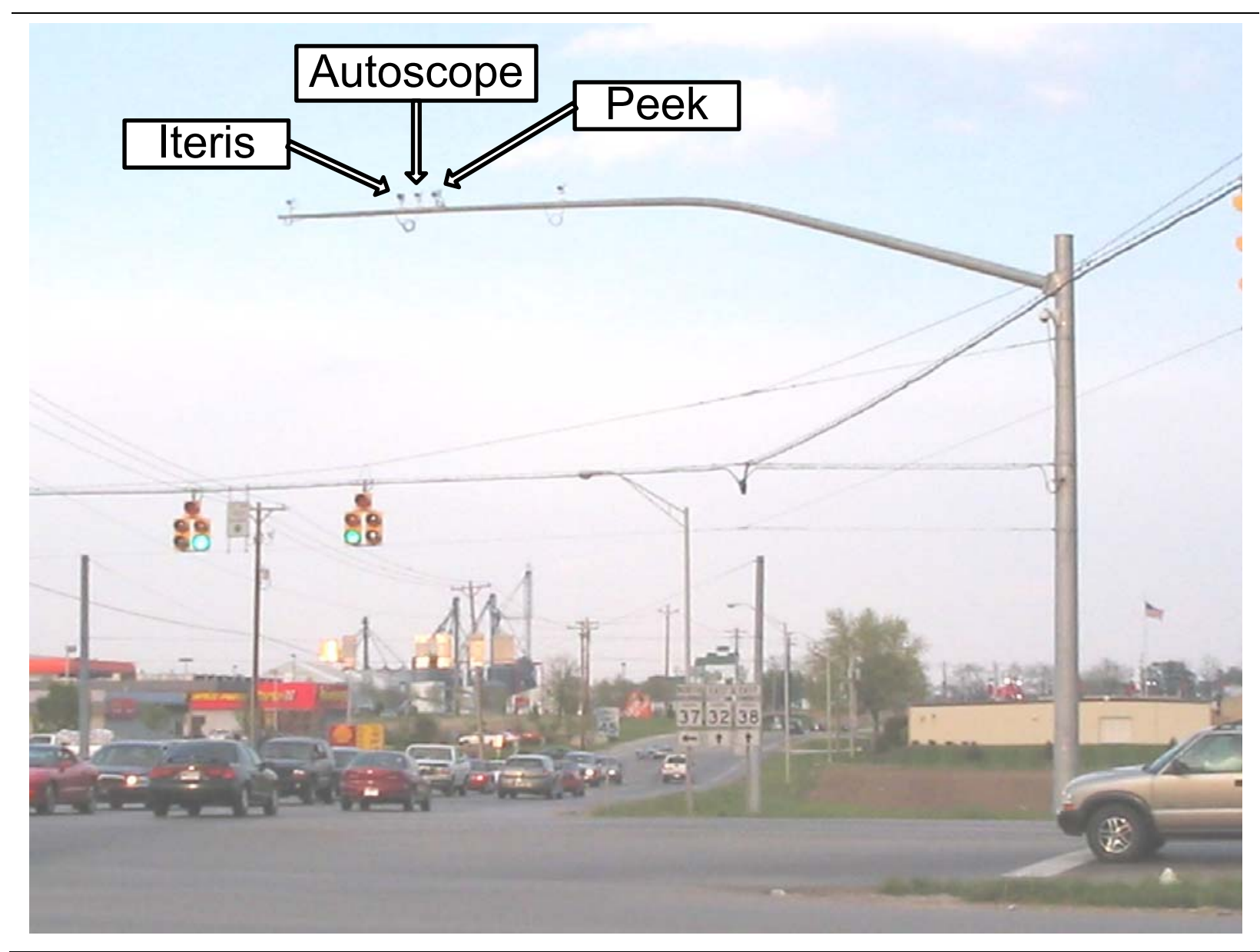

Figure 4-1: Camera Locations 


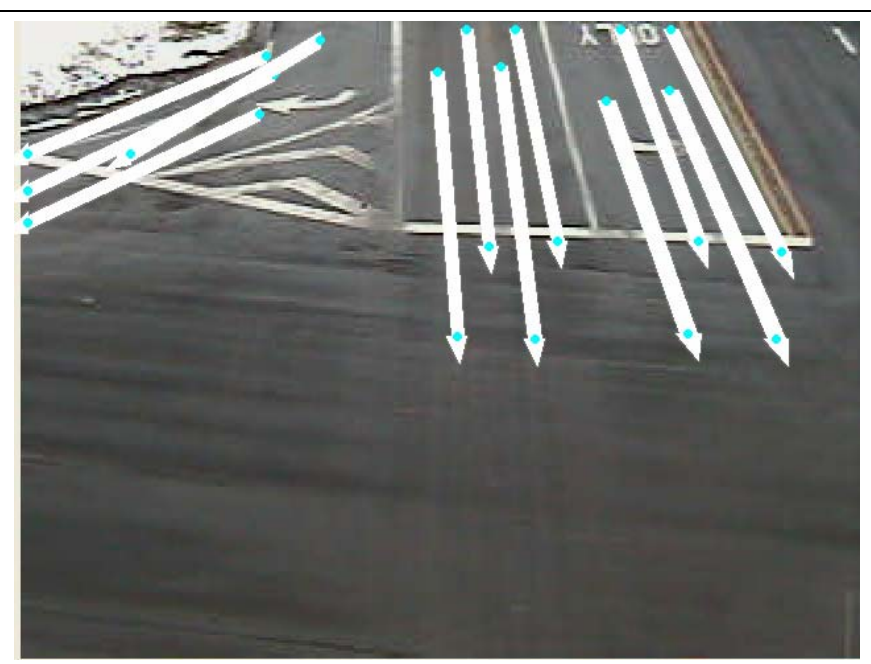

a) Autoscope

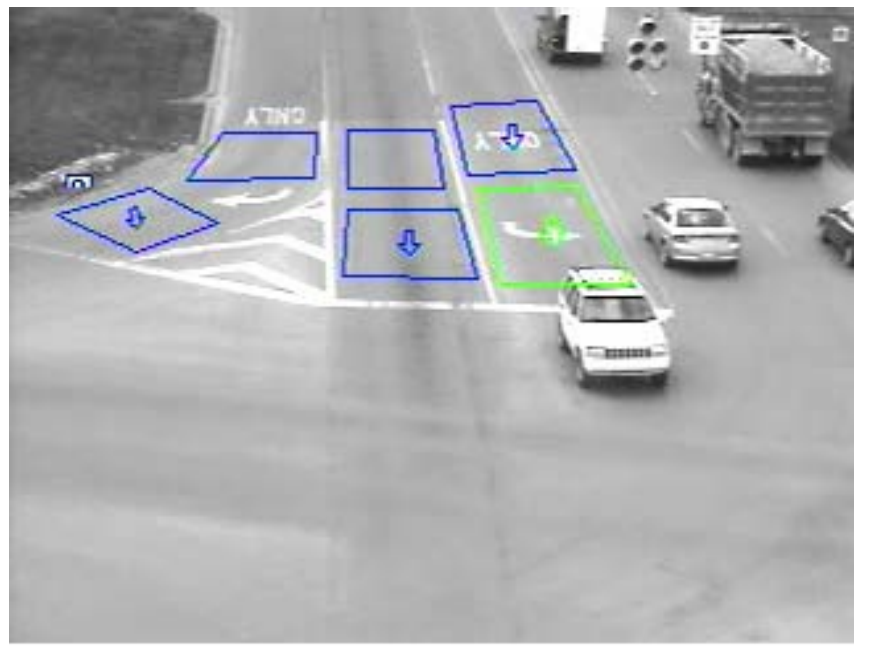

b) Peek

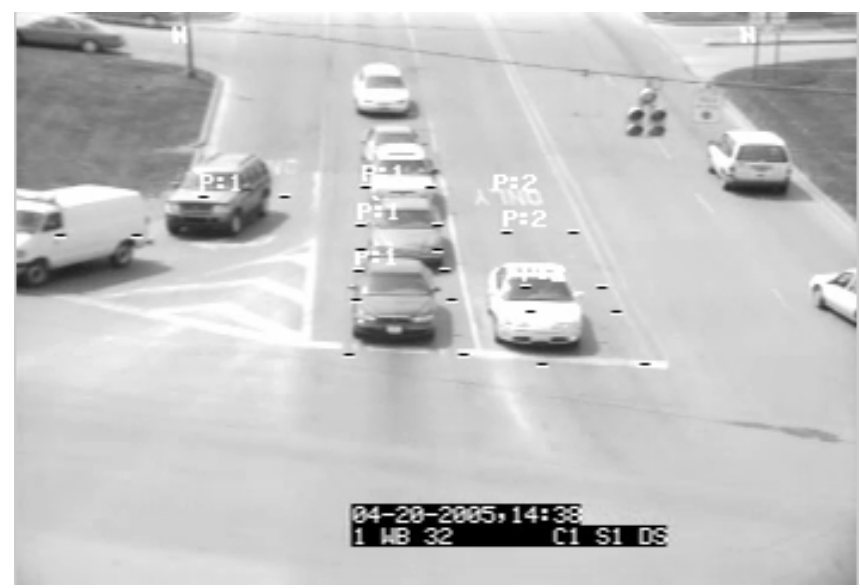

c) Iteris

Figure 4-2: Views from Camera with Detection Zones 


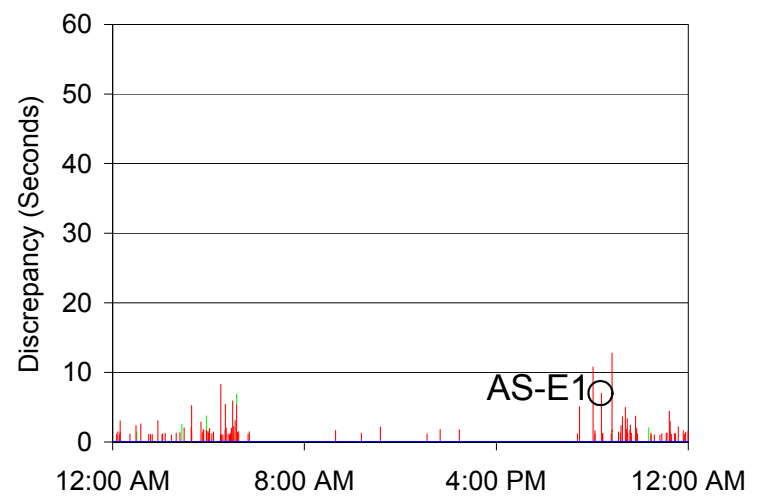

a) L1V0 Autoscope

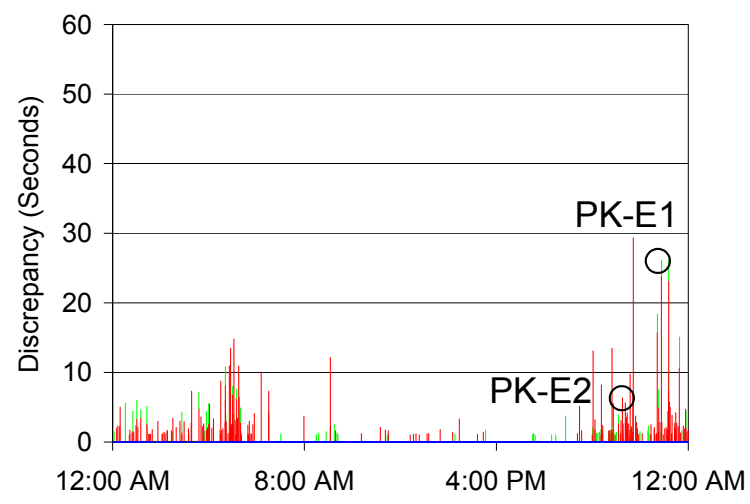

b) L1V0 Peek

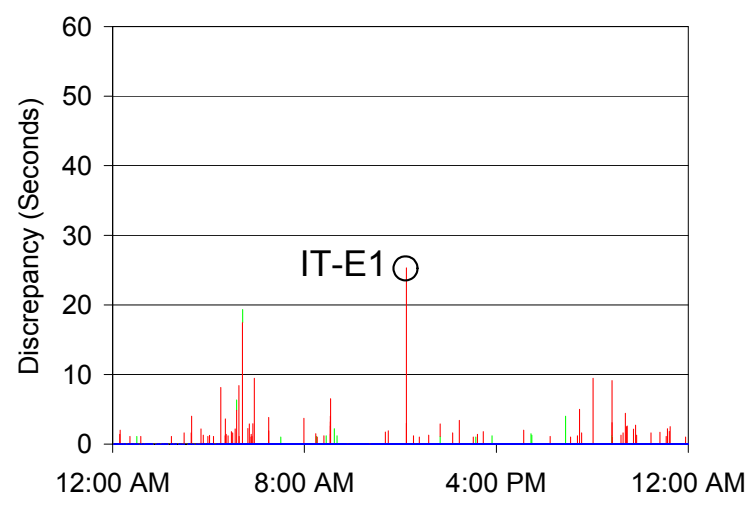

c) L1V0 Iteris

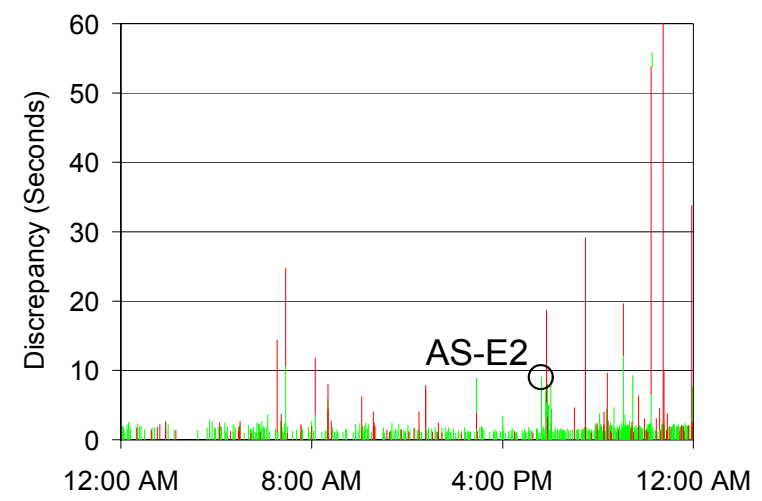

d) LOV1 Autoscope
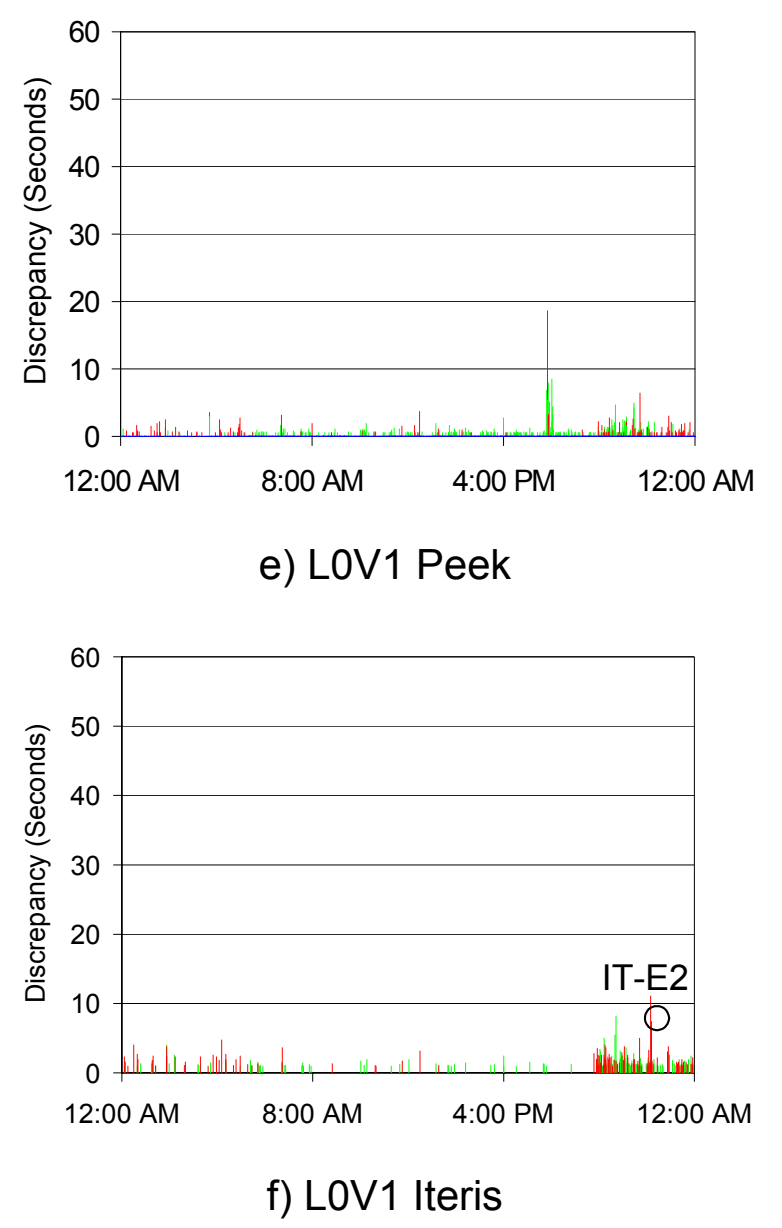

Figure 4-3: L1V0 and L0V1 Graphs for Through-Right Movement, May $2^{\text {nd }}, 2005$ 


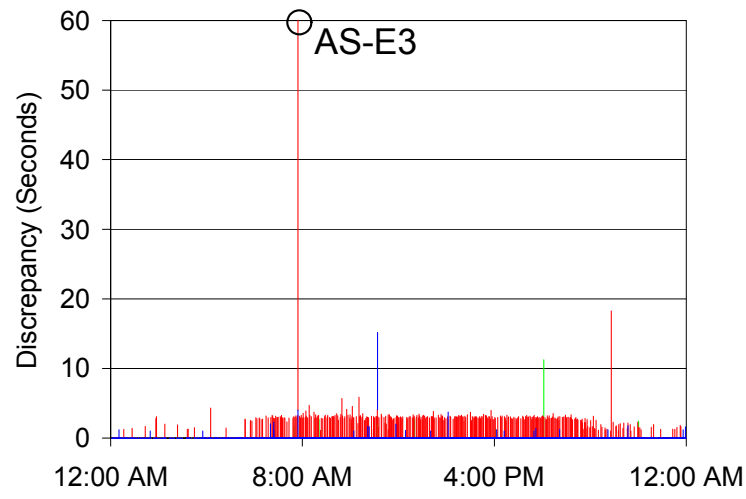

a) L1V0 Autoscope

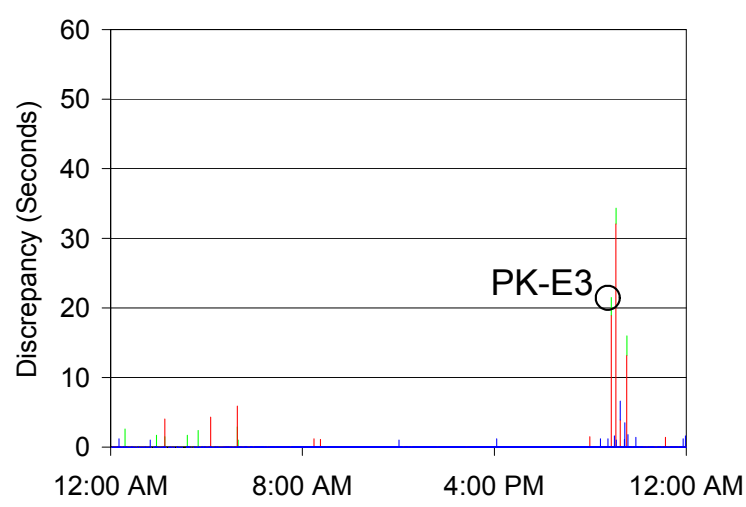

b) L1V0 Peek

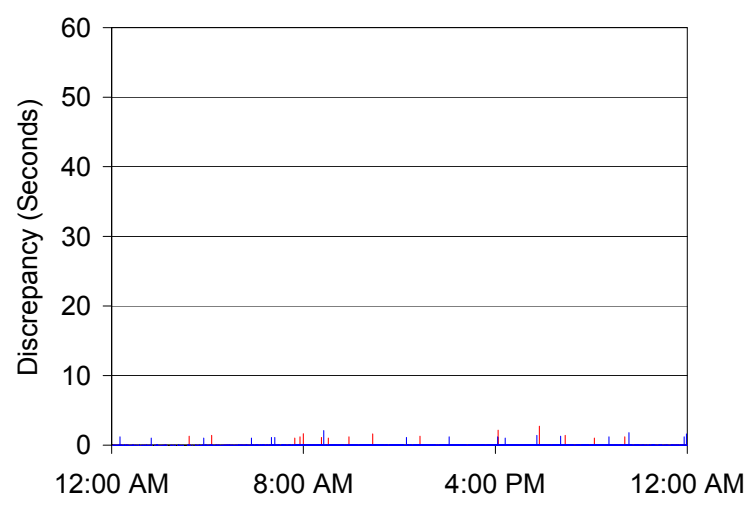

c) L1V0 Iteris

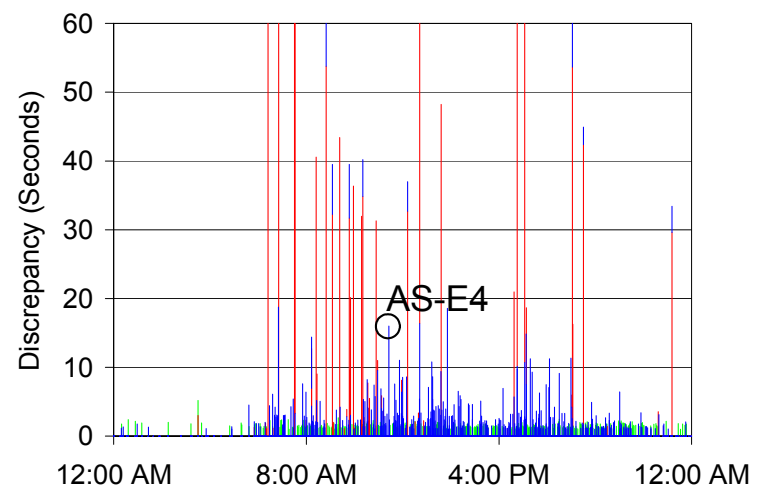

d) LOV1 Autoscope

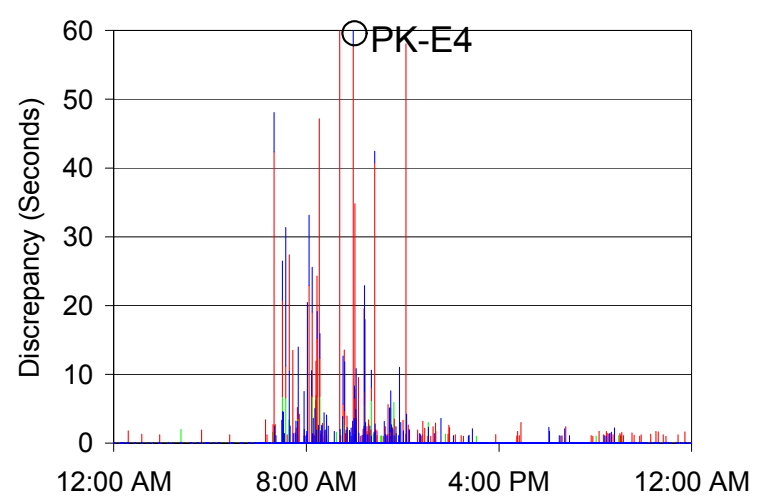

e) L0V1 Peek

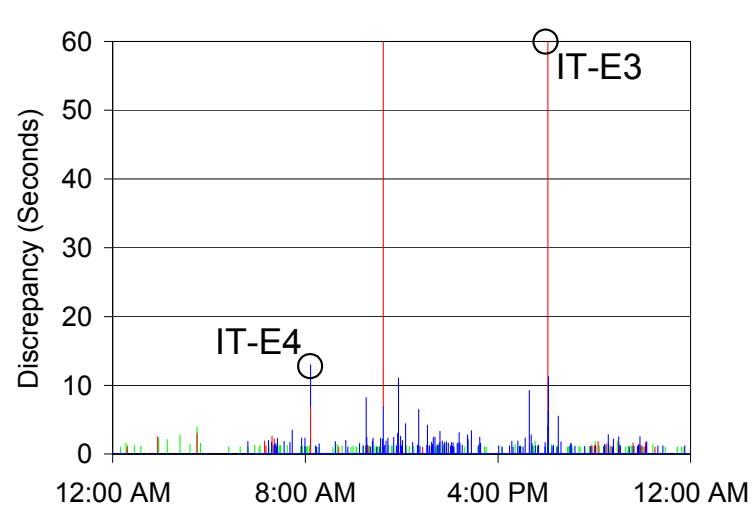

f) LOV1 Iteris

Figure 4-4: L1V0 and L0V1 Graphs for Left-Turn Movement, May 2 ${ }^{\text {nd }}, 2005$ 


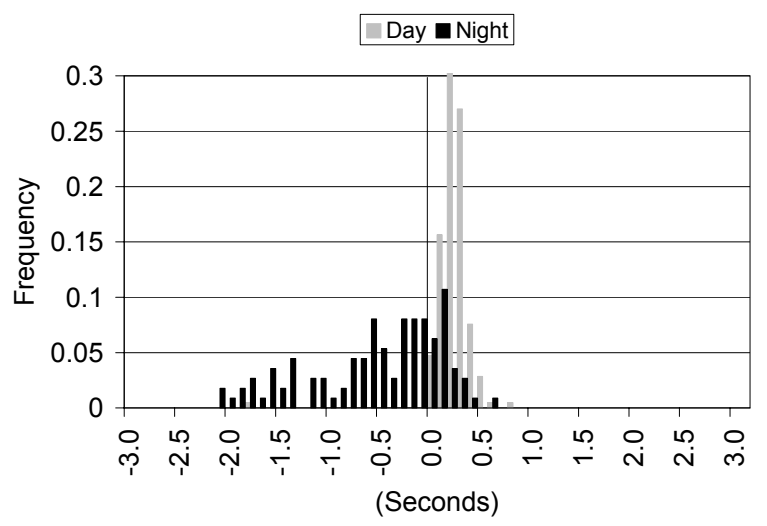

a) Activation Histogram Autoscope

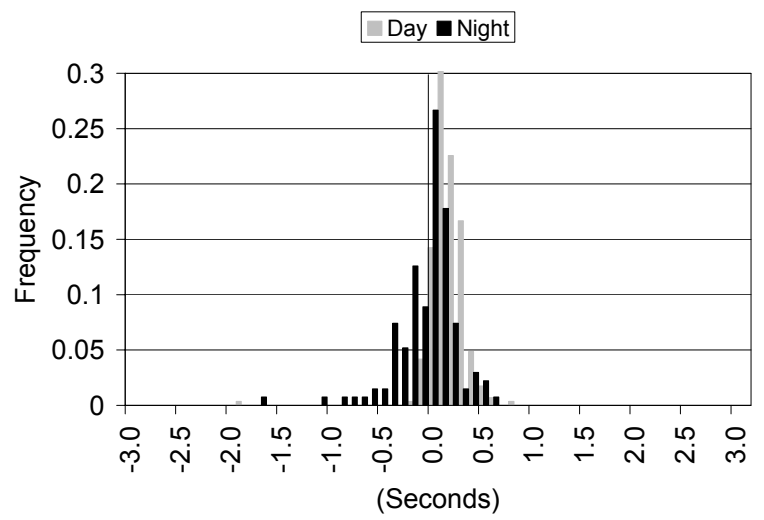

b) Activation Histogram Peek

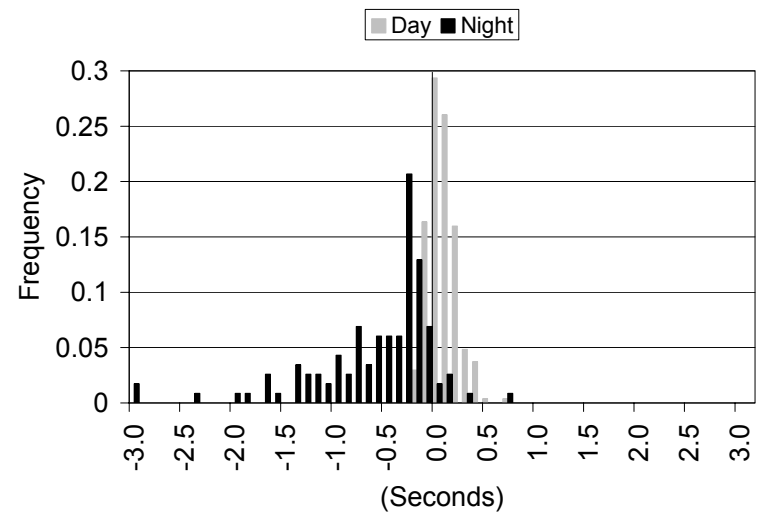

c) Activation Histogram Iteris

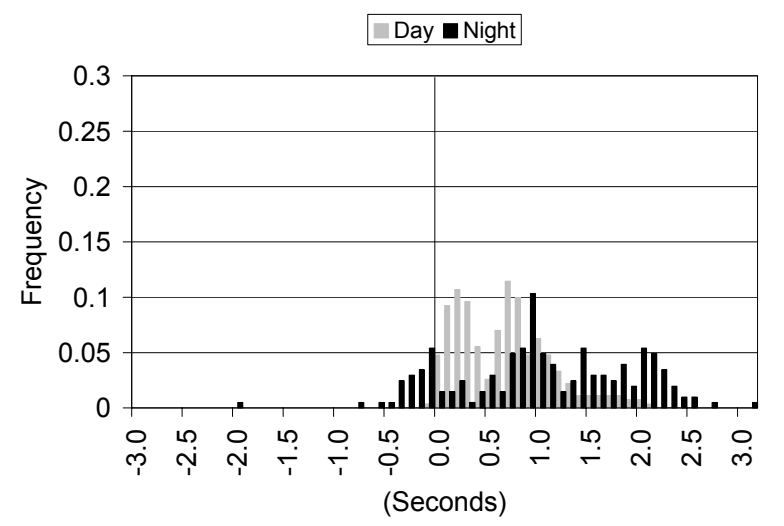

d) Deactivation Histogram Autoscope

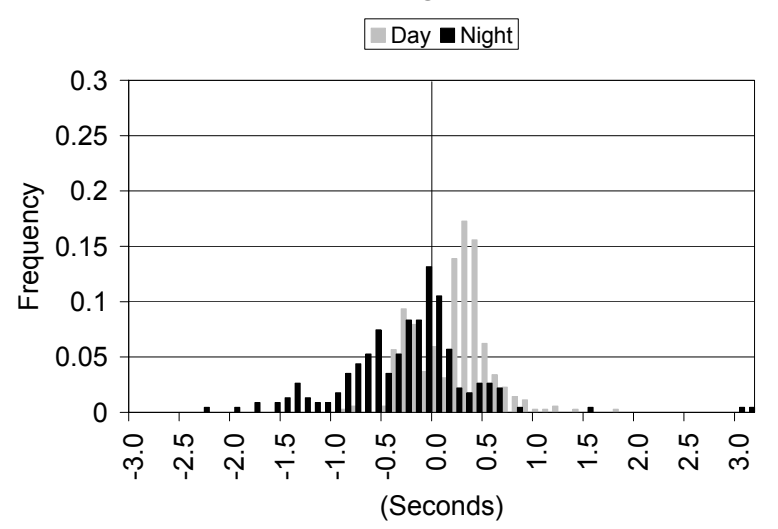

e) Deactivation Histogram Peek

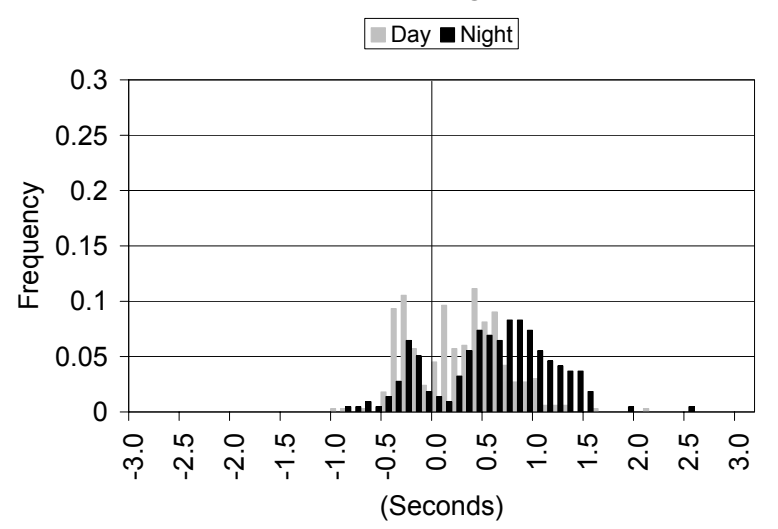

f) Deactivation Histogram Iteris

Figure 4-5: Activation and Deactivation Histograms for Through Movement, May $2^{\text {nd }}, 2005$ 


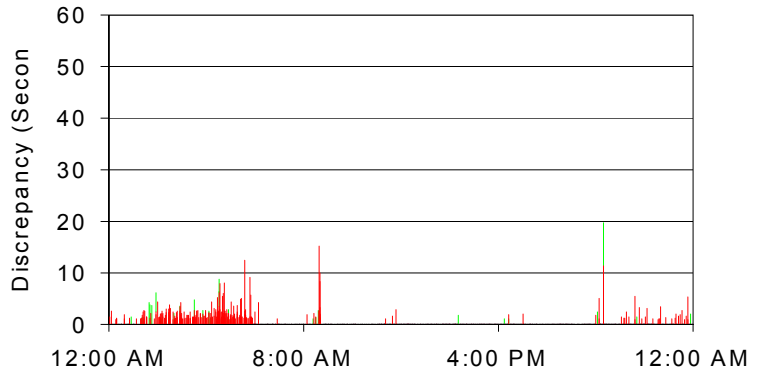

a) L1V0 Autoscope

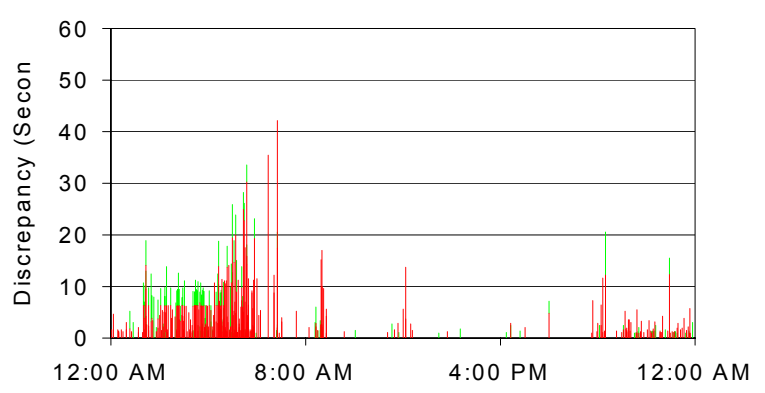

b) L1V0 Peek

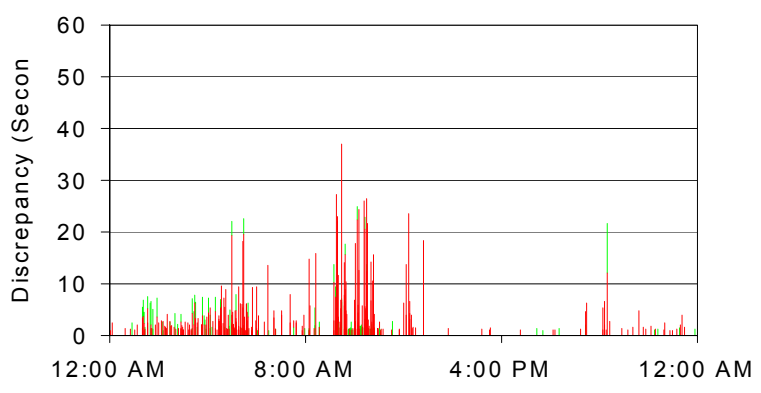

c) L1V0 Iteris

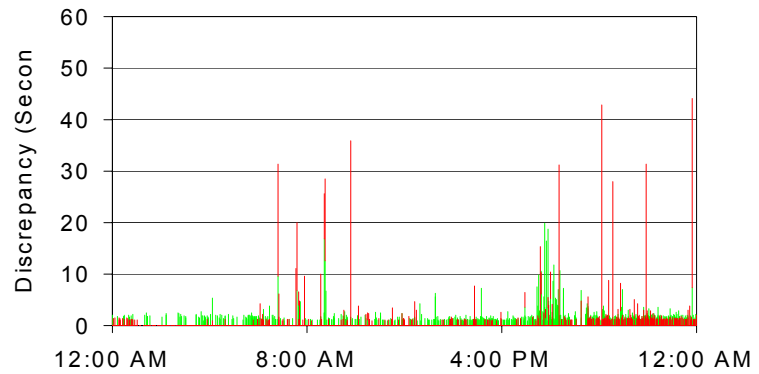

d) LOV1 Autoscope

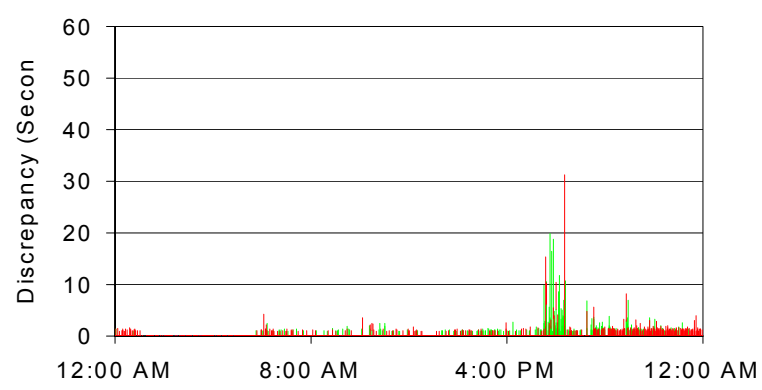

e) LOV1 Peek

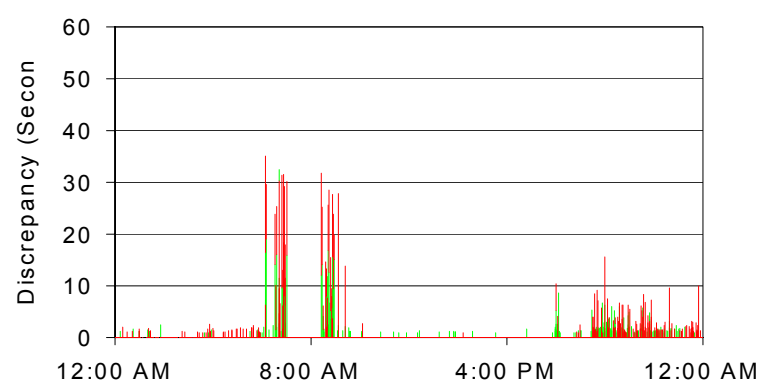

f) LOV1 Iteris

Figure 4-6: L1V0 and L0V1 Graphs for Through-Right Movement, September $21^{\text {st }}, 2005$ 


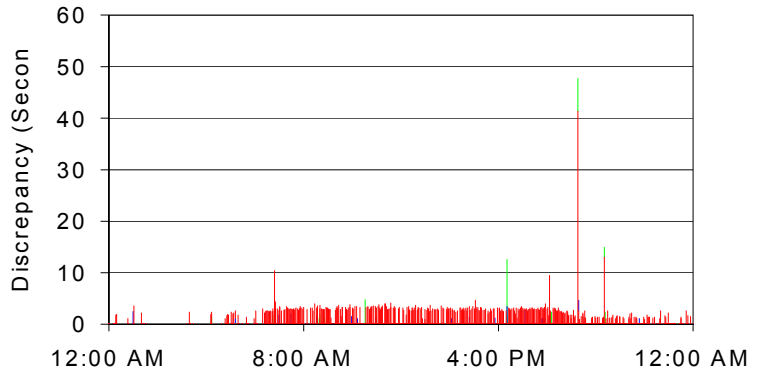

a) L1V0 Autoscope

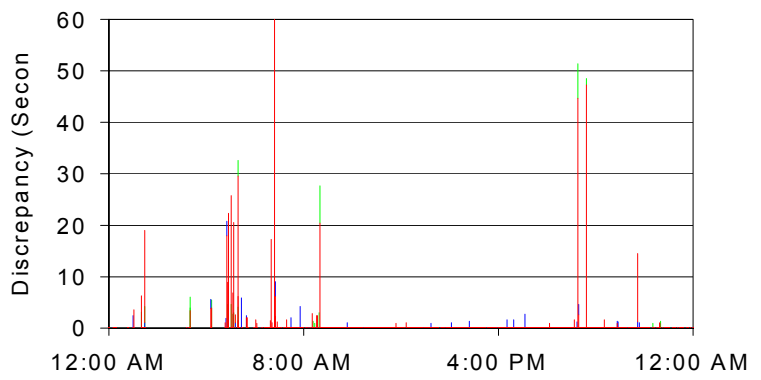

b) L1V0 Peek

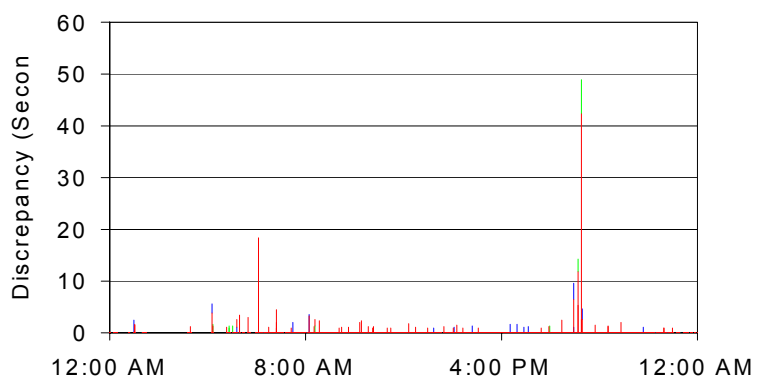

c) L1V0 Iteris

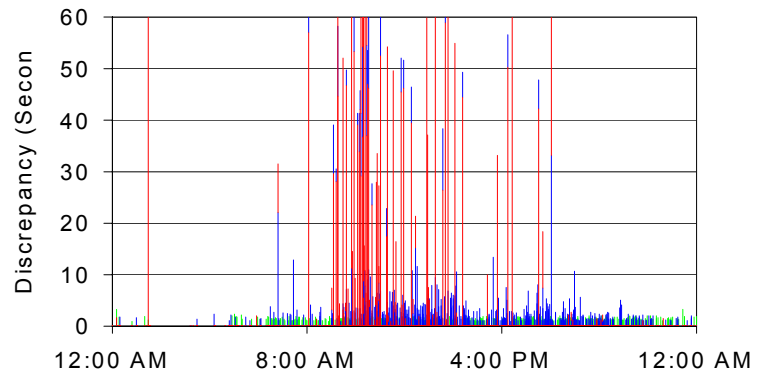

d) LOV1 Autoscope

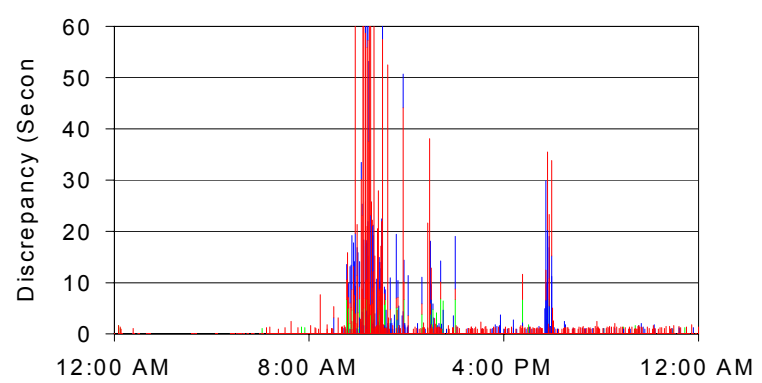

e) LOV1 Peek

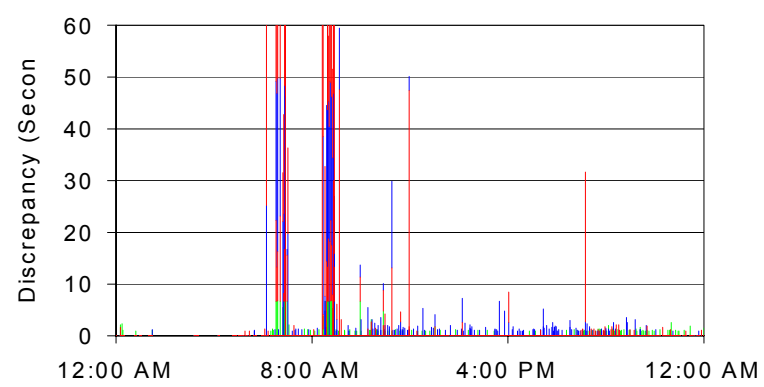

f) LOV1 Iteris

Figure 4-7: L1V0 and L0V1 Graphs for Left-Turn Movement, September $21^{\text {st }}$, 2005 


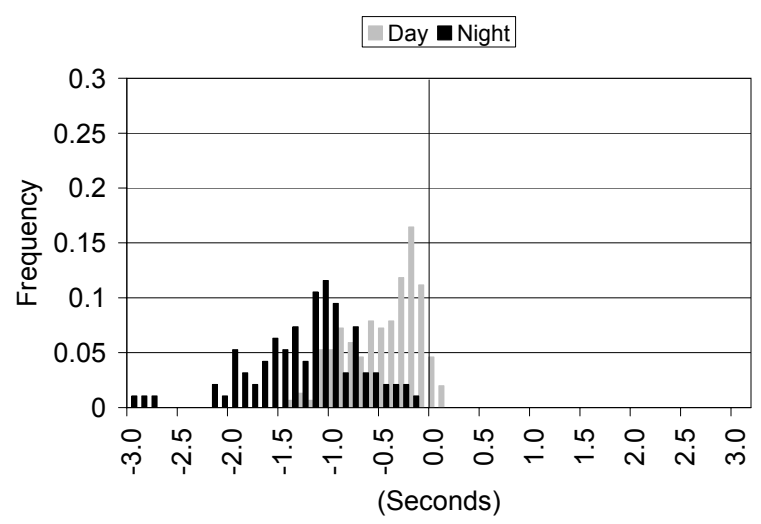

a) Activation Histogram Autoscope

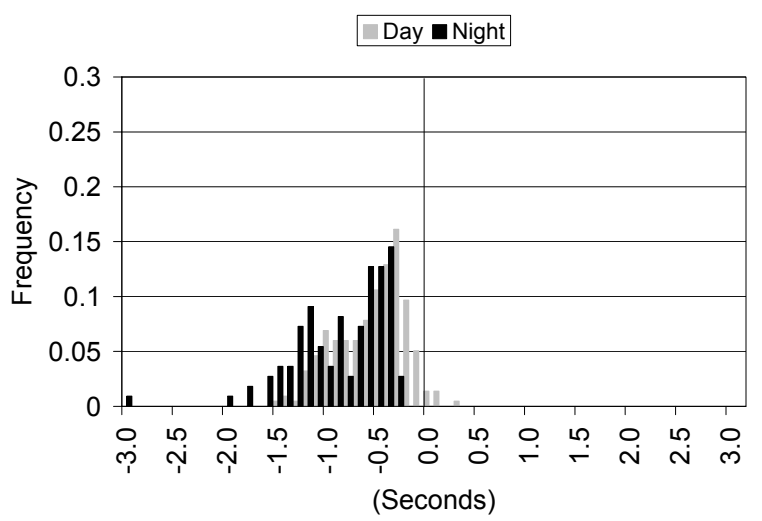

b) Activation Histogram Peek

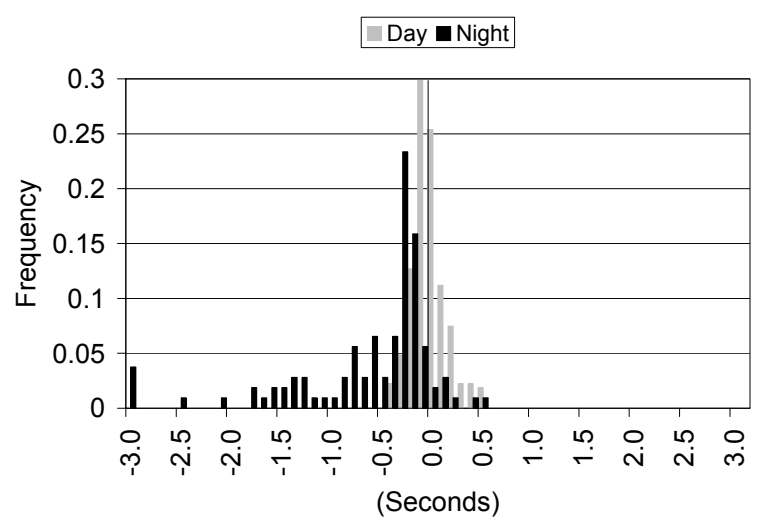

c) Activation Histogram Iteris

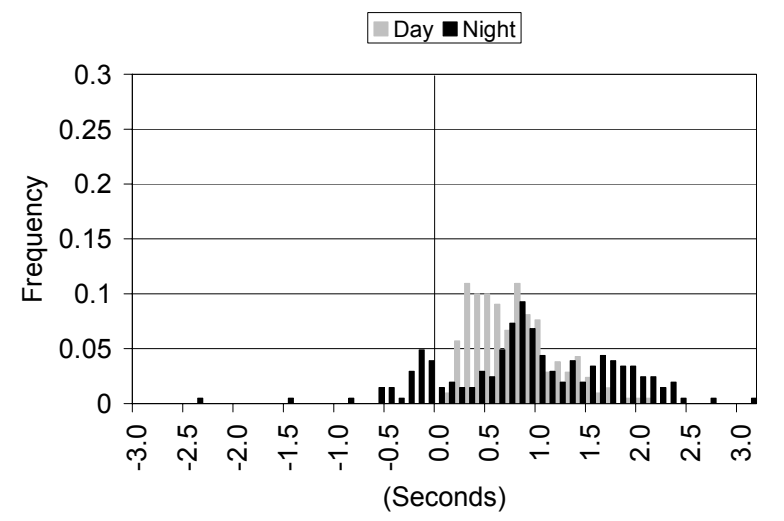

d) Deactivation Histogram Autoscope

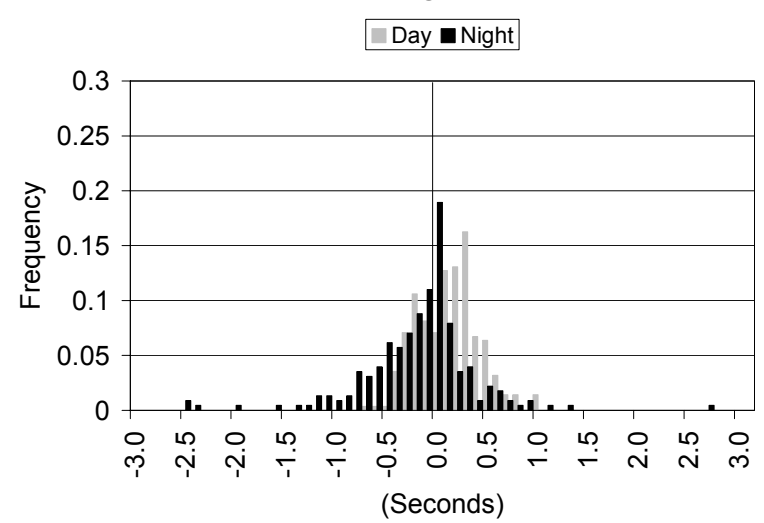

e) Deactivation Histogram Peek

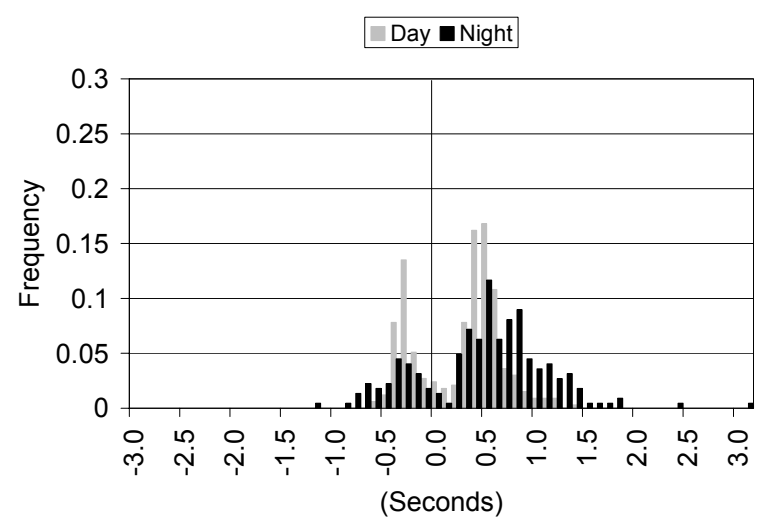

f) Deactivation Histogram Iteris

Figure 4-8: Activation and Deactivation Histograms for Through Movement, September $21^{\text {st }}, 2005$ 


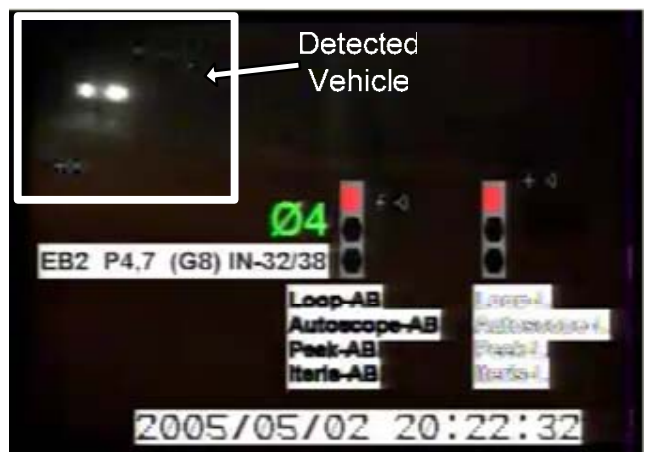

a) AS-E1: Vehicle in right turn lane is correctly detected.

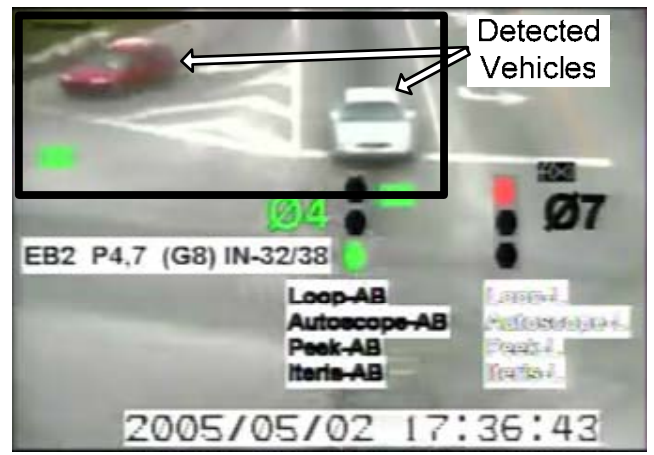

c) AS-E2: Vehicles are correctly detected in through-right lanes.

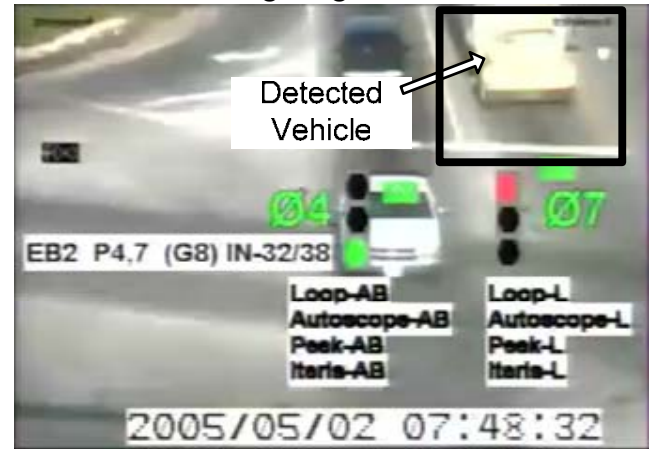

d) AS-E3: Vehicle in left-turn lane is correctly detected.

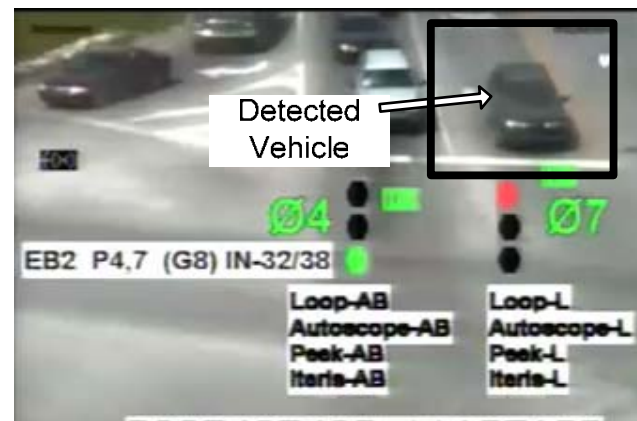

2005/05/02 11:25:22

f) AS-E4: Vehicle in left-turn lane is correctly detected.

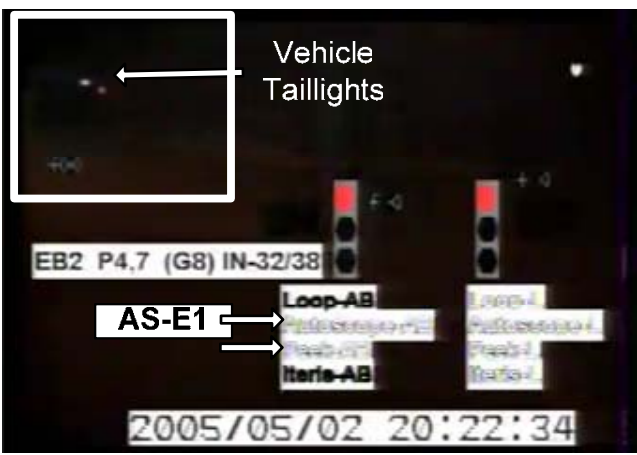

b) AS-E1: Vehicle in right turn lane is dropped when headlights are no longer visible.

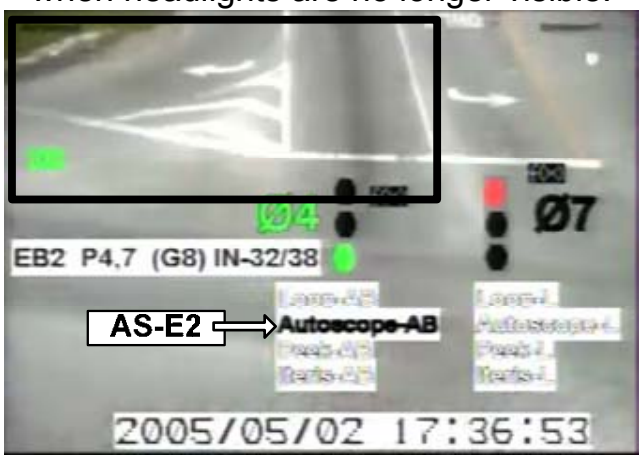

d) AS-E2: Vehicles depart through-right lanes but video detector maintains a call.

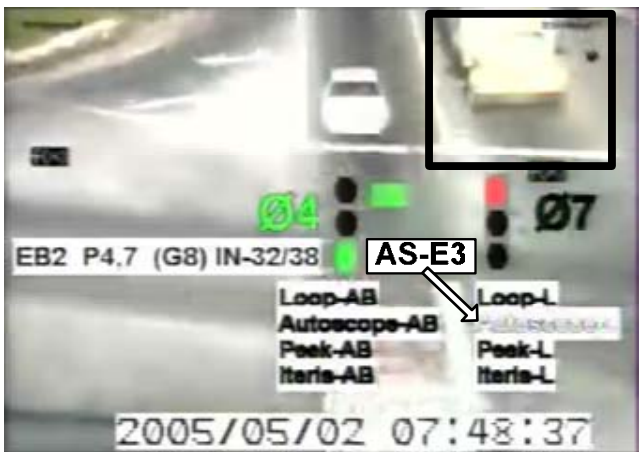

e) AS-E3: Vehicle call in left-turn lane is dropped by video detector.

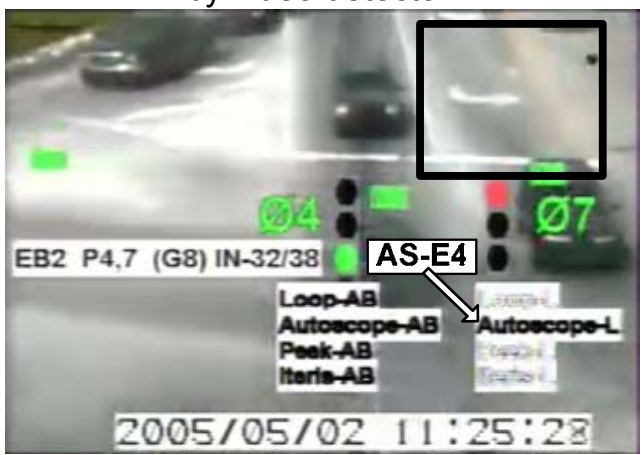

g) AS-E4: As vehicle creeps beyond stop-bar call is maintained.

Figure 4-9: Example Autoscope Errors 


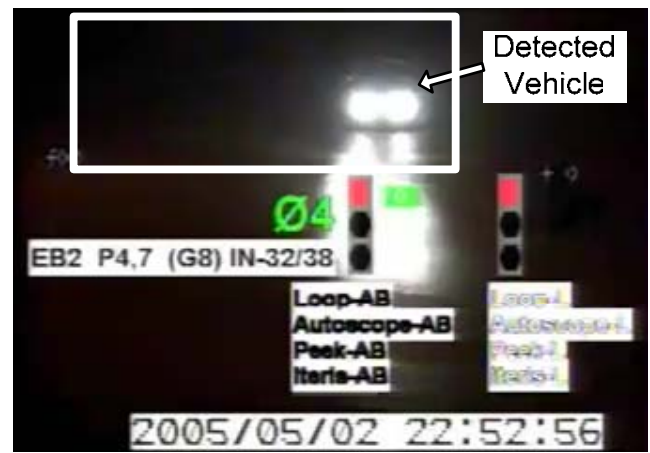

a) PK-E1: Vehicle in through lane is correctly detected.

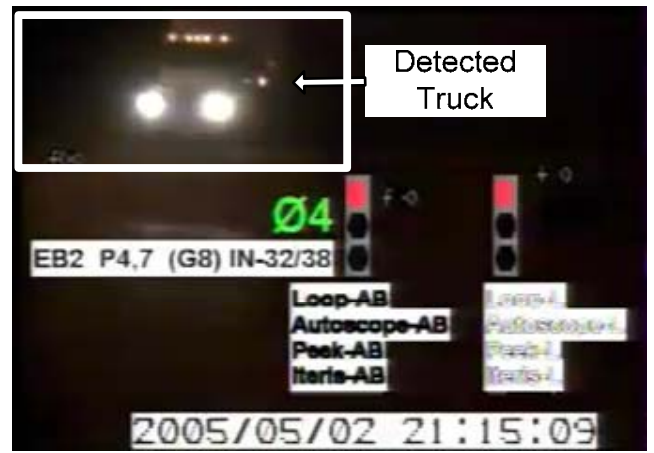

c) PK-E2: Truck is correctly detected in right-turn lane.

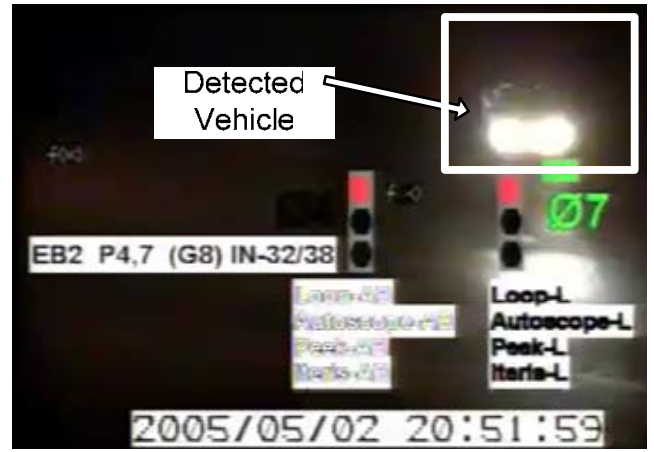

d) PK-E3: Vehicle in left-turn lane is correctly detected.

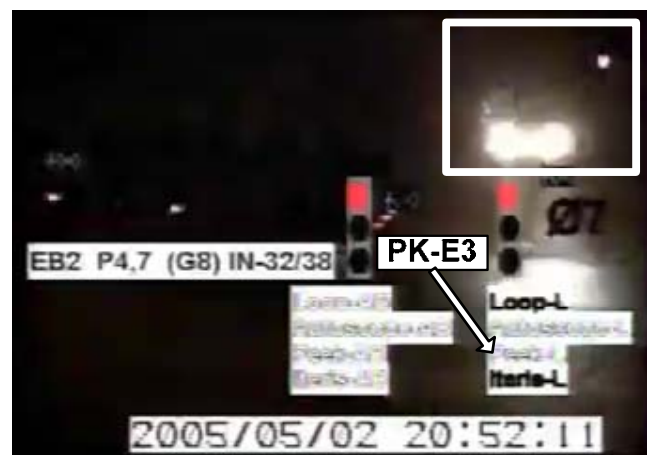

f) PK-E3: Call by vehicle in left-turn lane is dropped.

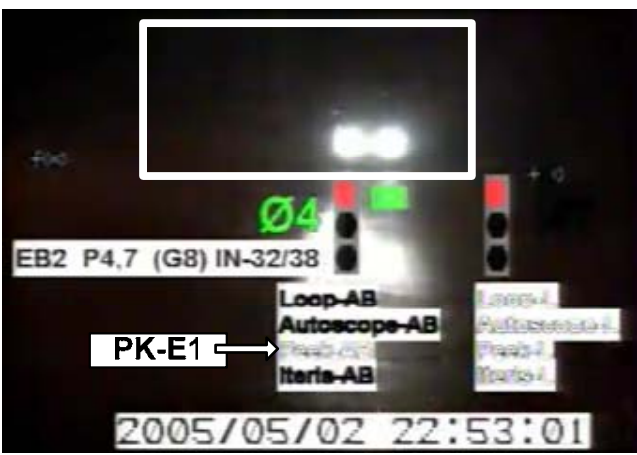

b) PK-E1: Vehicle in detection zone is dropped because headlights are past stop bar.

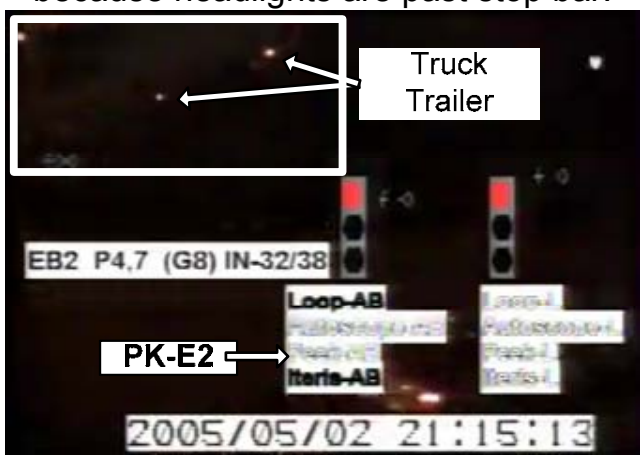

d) PK-E2: Truck is still in right turn lane but is not detected because headlights are not visible.

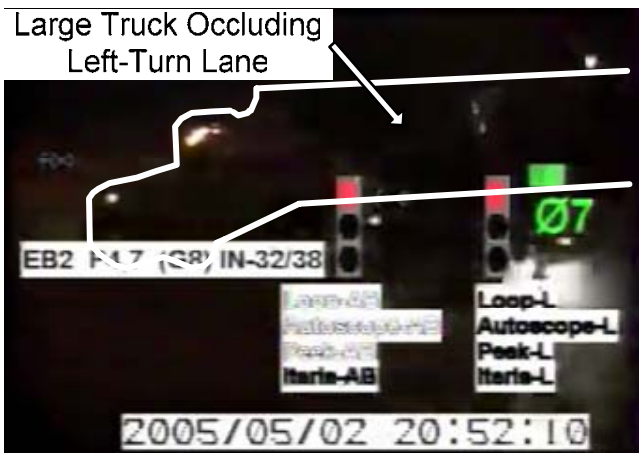

e) PK-E3: Truck traveling on cross street temporarily obscures left-turn lane.

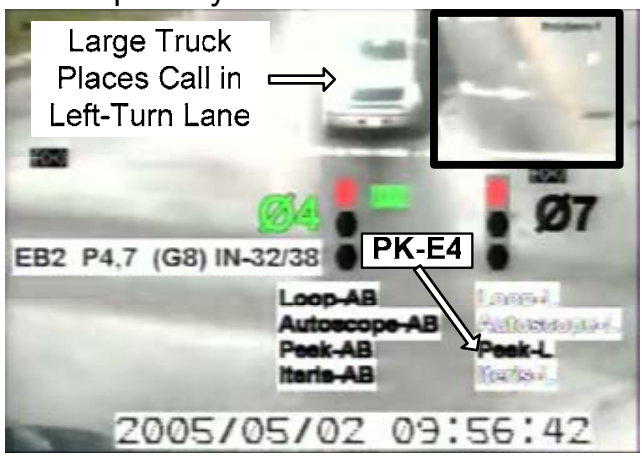

g) PK-E4: False call in left-turn lane, potentially because of large truck in through lane.

Figure 4-10: Example Peek Errors 


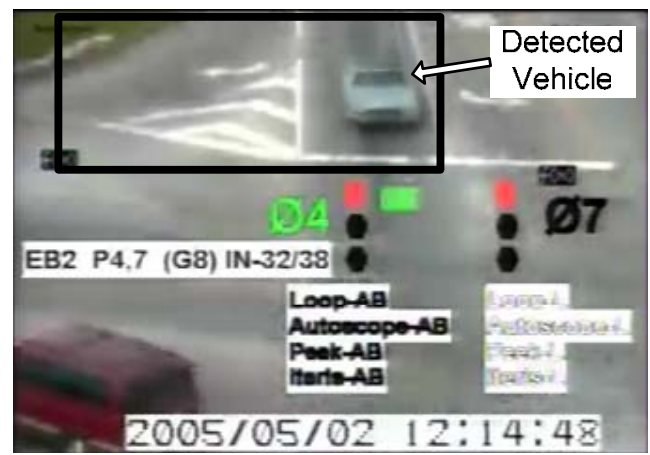

a) IT-E1: Vehicle in through lane is correctly detected.

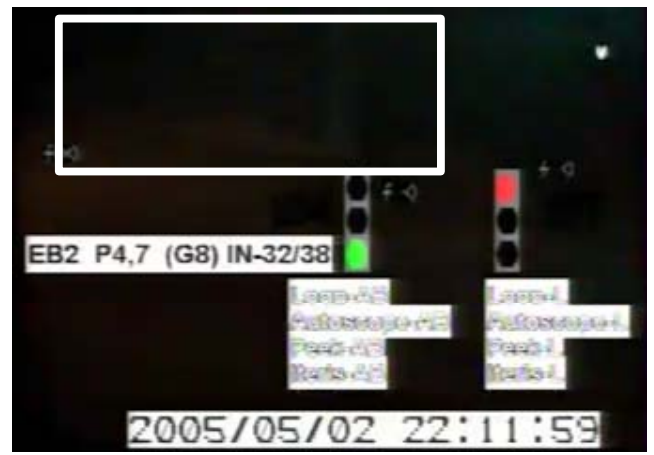

c) IT-E2: There is no calls in the through right lane.

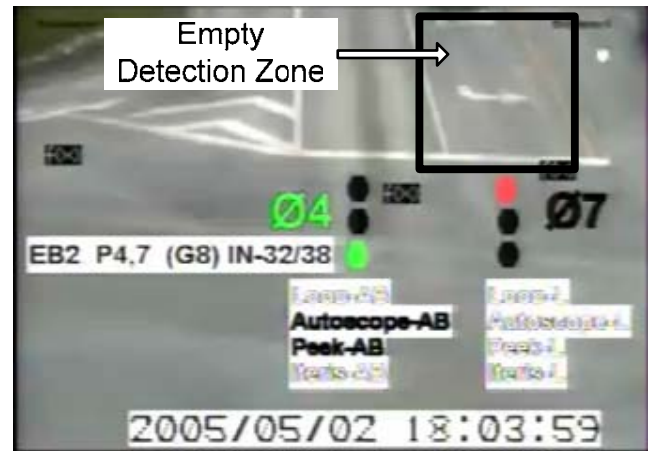

e) IT-E3: No call in left-turn lane.

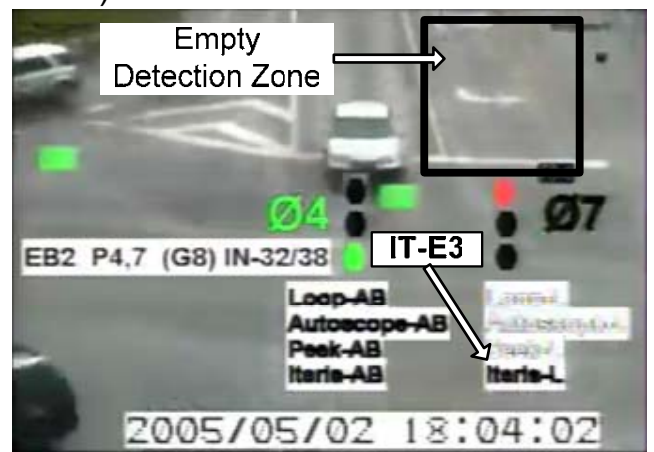

g) IT-E3: Video detection incorrectly maintains call in left-turn lane.

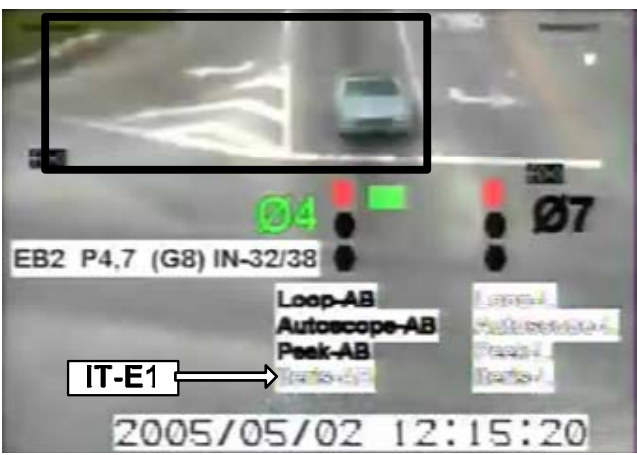

b) IT-E1: Vehicle call in through lane is dropped. No obvious reason for drop is observed.

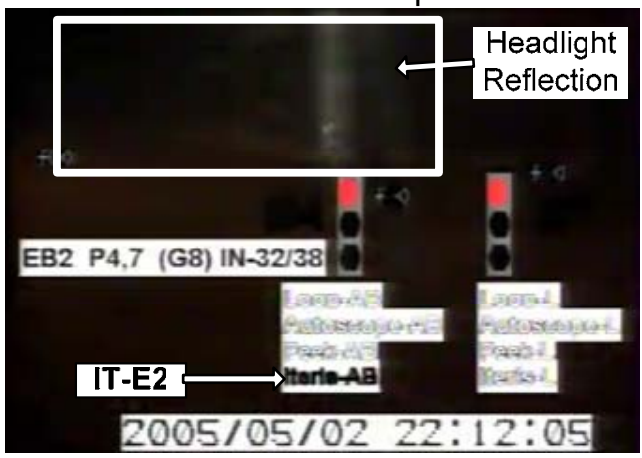

d) IT-E2: Headlight reflection on the pavement causes Iteris to activate early.

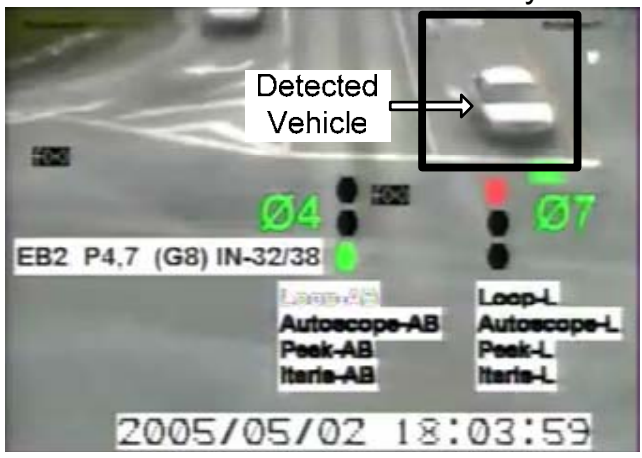

f) IT-E3: Vehicle places call in left-turn lane.

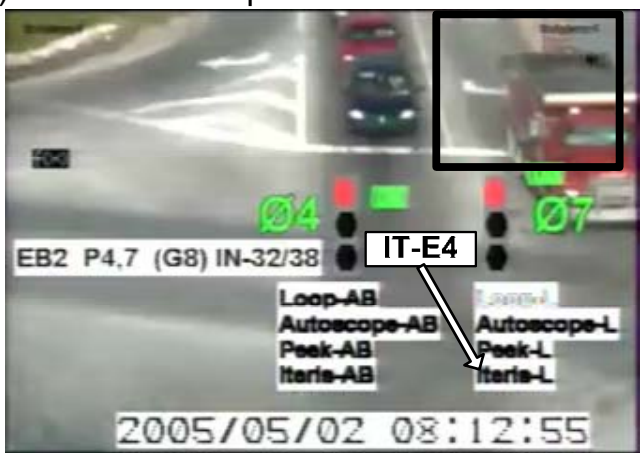

h) IT-E4: Large vehicle in Left-turn lane is beyond stop bar but still in video detection zones due to its' height.

Figure 4-11: Example Iteris Errors 


\begin{tabular}{|c|c|c|c|c|c|c|c|c|c|}
\hline \multirow{2}{*}{\multicolumn{2}{|c|}{ Error Type }} & & \multirow[b]{2}{*}{ 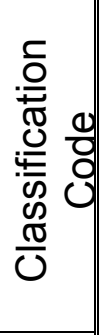 } & \multicolumn{2}{|c|}{ Autoscope } & \multicolumn{2}{|c|}{ Peek } & \multicolumn{2}{|c|}{ Iteris } \\
\hline & & & & 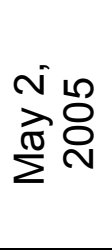 & 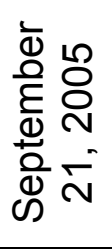 & 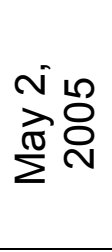 & 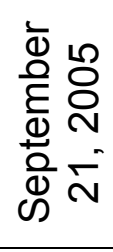 & 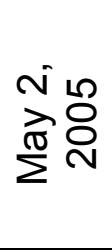 & 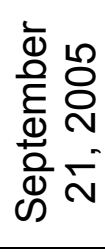 \\
\hline \multirow{6}{*}{$\underset{5}{\frac{5}{5}}$} & \multirow{3}{*}{ 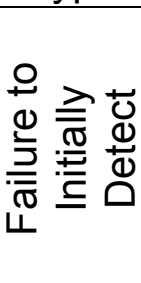 } & $\begin{array}{l}\text { Dark colored } \\
\text { vehicle }\end{array}$ & A1 & 1 & 2 & 0 & 0 & 0 & 0 \\
\hline & & $\begin{array}{l}\text { Vehicle creeps } \\
\text { slowly to stop bar }\end{array}$ & $\mathrm{A} 2$ & 2 & 0 & 0 & 0 & 0 & 0 \\
\hline & & Unexplained & A3 & 0 & 0 & 0 & 13 & 0 & 1 \\
\hline & \multirow{3}{*}{ 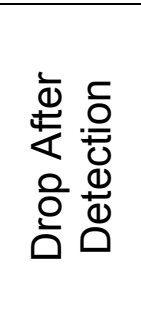 } & $\begin{array}{l}\text { Headlights in front } \\
\text { of stop bar }\end{array}$ & B1 & 0 & 1 & 4 & 4 & 0 & 2 \\
\hline & & $\begin{array}{l}\text { Occlusion from } \\
\text { cross-street vehicle } \\
\text { (Truck Wipe) }\end{array}$ & B2 & 1 & 1 & 2 & 0 & 0 & 2 \\
\hline & & Unexplained & B3 & 2 & 0 & 0 & 3 & 0 & 1 \\
\hline \multirow{8}{*}{ 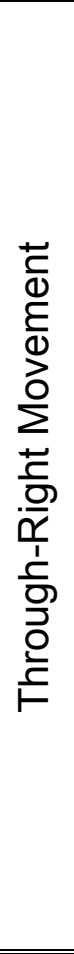 } & \multirow{3}{*}{ 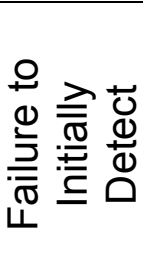 } & $\begin{array}{l}\text { Dark colored } \\
\text { vehicle }\end{array}$ & A1 & 0 & 1 & 14 & 0 & 2 & 0 \\
\hline & & $\begin{array}{l}\text { Vehicle creeps } \\
\text { slowly to stop bar }\end{array}$ & $\mathrm{A} 2$ & 0 & 0 & 0 & 0 & 0 & 1 \\
\hline & & Unexplained & A3 & 0 & 1 & 0 & 82 & 0 & 11 \\
\hline & \multirow{5}{*}{ 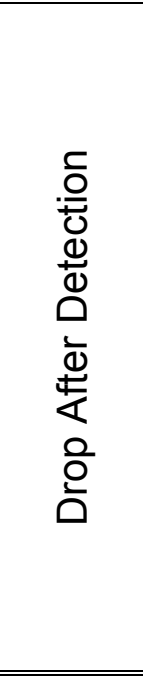 } & $\begin{array}{l}\text { Headlights in front } \\
\text { of stop bar (through } \\
\text { lane) }\end{array}$ & B1 & 0 & 0 & 14 & 2 & 2 & 1 \\
\hline & & $\begin{array}{l}\text { Occlusion from } \\
\text { cross-street vehicle } \\
\text { (Truck Wipe) }\end{array}$ & B2 & 0 & 1 & 0 & 0 & 0 & 2 \\
\hline & & Unexplained & B3 & 0 & 2 & 0 & 12 & 0 & 56 \\
\hline & & $\begin{array}{l}\text { Right-turning } \\
\text { vehicle pulls very } \\
\text { far forward }\end{array}$ & B4 & 8 & 14 & 25 & 31 & 6 & 22 \\
\hline & & $\begin{array}{l}\text { Car pulls in front of } \\
\text { stop bar then backs } \\
\text { up }\end{array}$ & B5 & 0 & 0 & 1 & 0 & 1 & 0 \\
\hline \multicolumn{3}{|c|}{ Missed Calls (Total) } & & 14 & 23 & 46 & 147 & 9 & 99 \\
\hline
\end{tabular}

Table 4-1: Tabulation of Missed Calls Longer than 5 seconds 


\begin{tabular}{|c|c|}
\hline 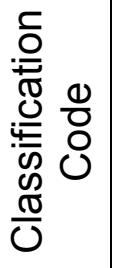 & Description (Missed Calls) \\
\hline A1 & $\begin{array}{l}\text { Failure to Initially Detect - Vehicle was not initially detected when it entered } \\
\text { the detection zone, likely due to it's dark color which was similar to the } \\
\text { pavement background. }\end{array}$ \\
\hline $\mathrm{A} 2$ & $\begin{array}{l}\text { Failure to Initially Detect - Vehicle slowly creeps into the detection zone and is } \\
\text { not initially detected by the video detector. }\end{array}$ \\
\hline A3 & Failure to Initially Detect - No observable cause is apparent on the video. \\
\hline B1 & $\begin{array}{l}\text { Dropped Call After Initial Detection - A is still in the detection zone, but its } \\
\text { headlights are beyond the stop bar causing the video detector to drop the call. }\end{array}$ \\
\hline B2 & $\begin{array}{l}\text { Dropped Call After Initial Detection - A vehicle is correctly detected by the } \\
\text { video detector, then dropped. Occurs after a vehicle (usually a large truck) } \\
\text { traveling on the cross-street temporarily occludes the detected vehicle causing } \\
\text { the call to be dropped. }\end{array}$ \\
\hline B3 & $\begin{array}{l}\text { Dropped Call After Initial Detection - A vehicle is correctly detected by the } \\
\text { video detector, then dropped. No observable cause for the dropped call is } \\
\text { apparent on the video. }\end{array}$ \\
\hline B4 & $\begin{array}{l}\text { Dropped Call After Initial Detection - A vehicle in the right turn lane pulls very } \\
\text { far forward so that it's headlights are outside of the detection zone causing the } \\
\text { video detector to drop the call. At locations where vehicles are permitted to } \\
\text { turn right on red, drivers have the tendency to pull ahead of the stop bar. Since } \\
\text { these drivers may eventually accept a gap in cross-street traffic without a } \\
\text { signal change, these types of errors are less critical than other types of missed } \\
\text { call errors. }\end{array}$ \\
\hline B5 & $\begin{array}{l}\text { Dropped Call After Initial Detection - A vehicle pulls out of the detection zone, } \\
\text { then backs up into the detection zone. Some video detectors utilize directional } \\
\text { logic to prevent false calls from vehicles traveling in the opposite direction who } \\
\text { may cross the detection zone. However, in this case, a missed call error } \\
\text { occurs. }\end{array}$ \\
\hline
\end{tabular}

Table 4-2: Missed Call Error Classification Code 


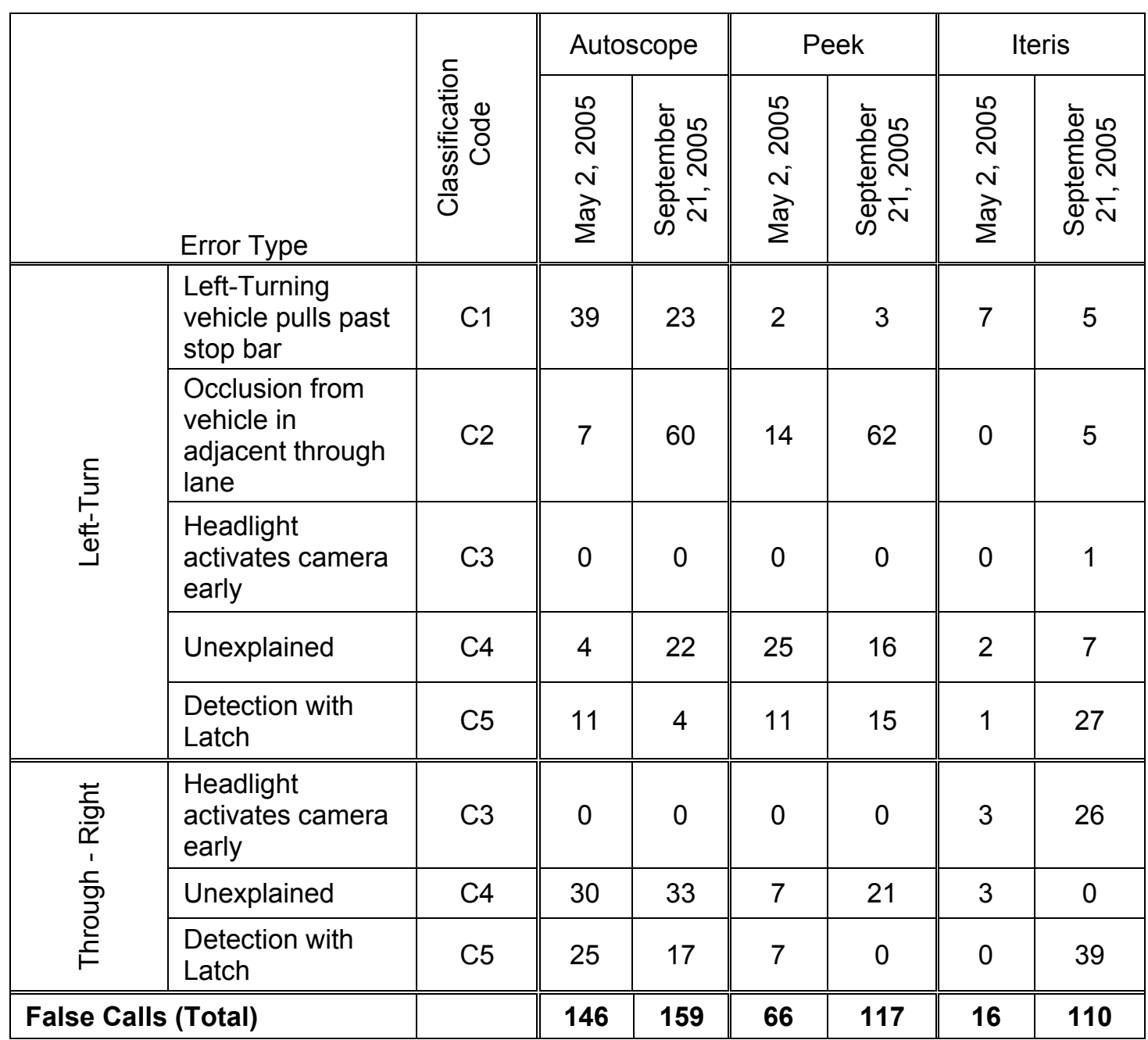

a) False Calls

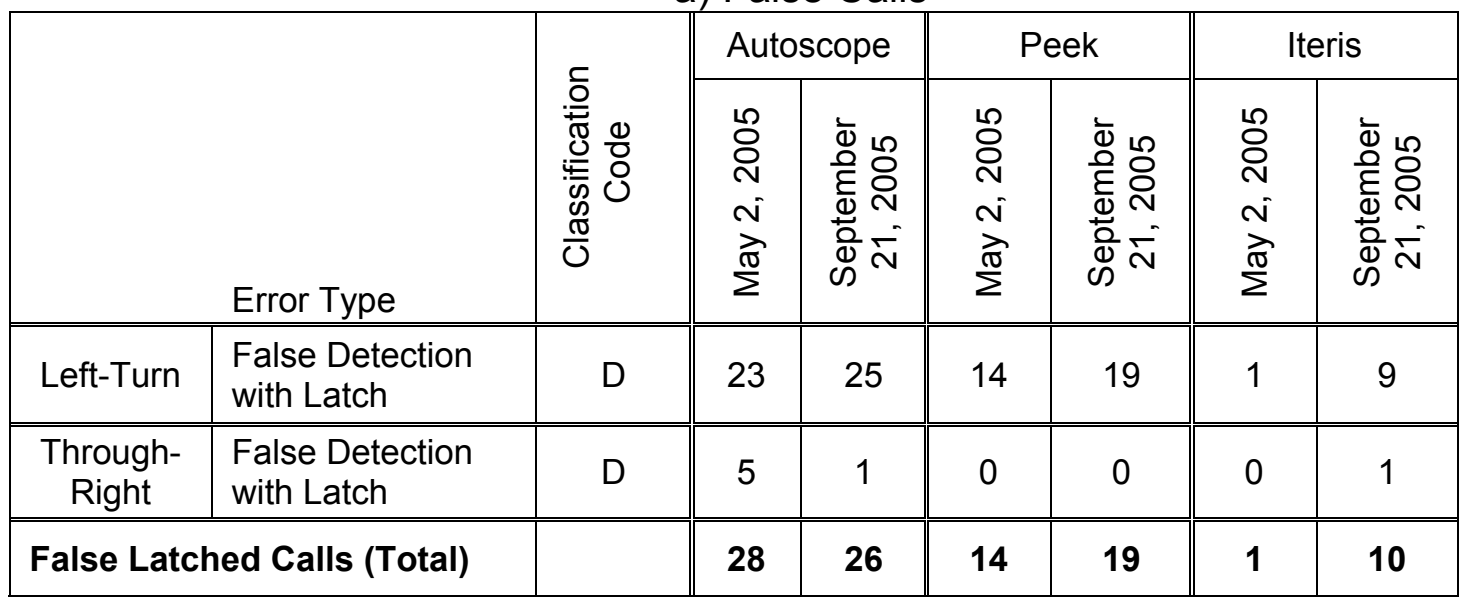

b) False Latched Calls

Table 4-3: Tabulation of False Calls Longer than 5 seconds 


\begin{tabular}{|c|c|}
\hline 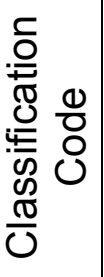 & Description (False \& Latched Calls) \\
\hline C1 & $\begin{array}{l}\text { False Detection - A left-turning vehicle enters the intersection while awaiting a } \\
\text { gap in opposing traffic. The vehicle leaves the detection zone, but the call is } \\
\text { not dropped by the video detector. }\end{array}$ \\
\hline $\mathrm{C} 2$ & $\begin{array}{l}\text { False Detection - A vehicle (usually a large truck) in the through lane } \\
\text { immediately adjacent to the left-turn lane causes the video detector to place a } \\
\text { call in the left-turn lane because of a shadow or because of occlusion from the } \\
\text { height of the vehicle. }\end{array}$ \\
\hline C3 & $\begin{array}{l}\text { False Detection - Headlight reflection off of the pavement causes a video } \\
\text { detector to activate prior to the vehicle actually arriving at the detection zone. }\end{array}$ \\
\hline $\mathrm{C} 4$ & $\begin{array}{l}\text { False Detection - Detection reported when no vehicle present or near } \\
\text { detection zone. Detection ceases when either the causal image artifact is no } \\
\text { longer present or after } 5 \text { seconds. }\end{array}$ \\
\hline C5 & False Detection with Latch - False detection which stays on indefinitely. \\
\hline $\mathrm{D}$ & $\begin{array}{l}\text { Detection with Latch - A vehicle is detected when present in a detection zone, } \\
\text { stays continuously detected while in the zone, but detection does not } \\
\text { deactivate after it leaves the zone. }\end{array}$ \\
\hline
\end{tabular}

Table 4-4: False \& Latched Call Error Classification Code 


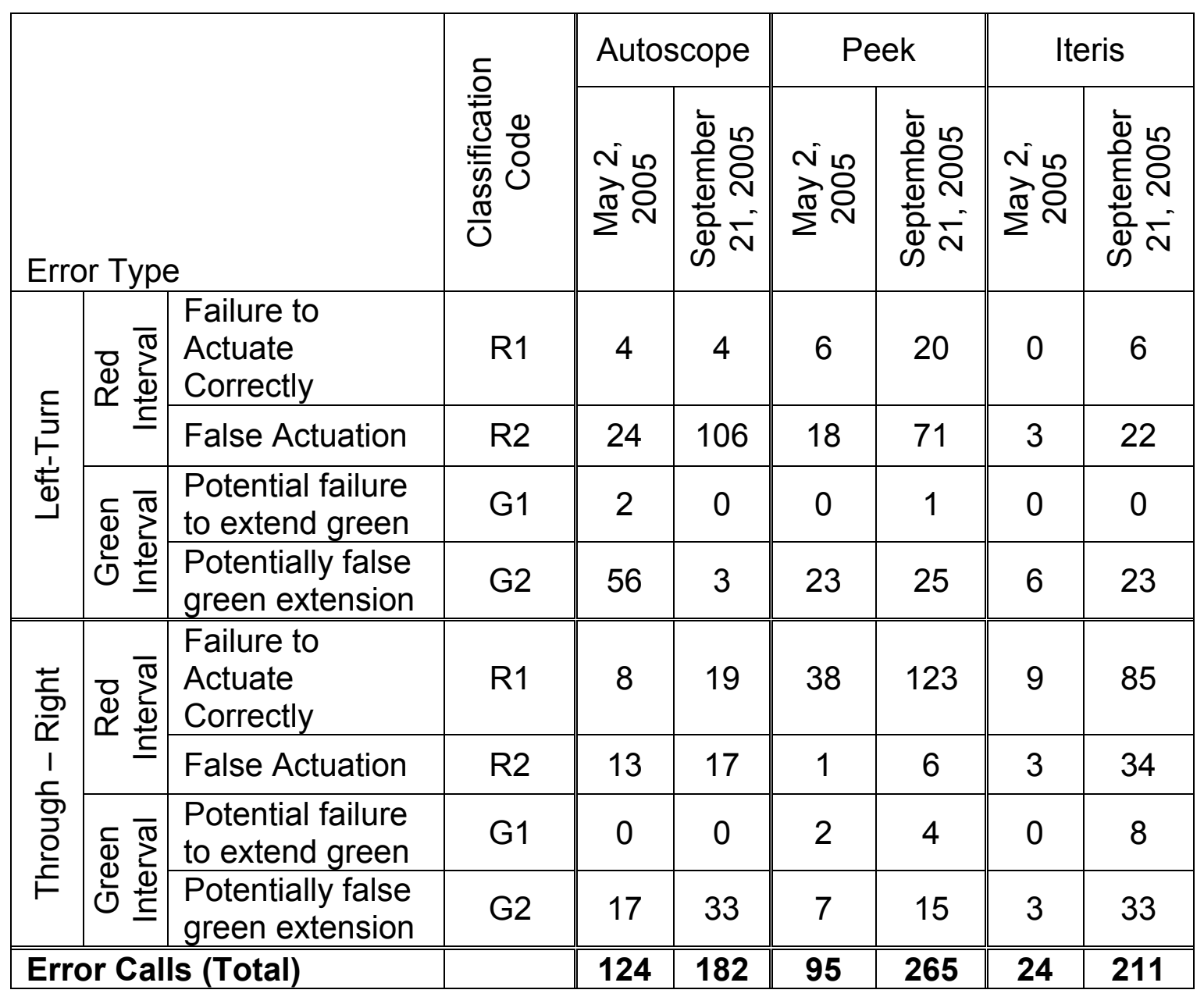

Table 4-5: Tabulation of Detector Error Impacts on Signal Operations 


\begin{tabular}{|c|c|}
\hline 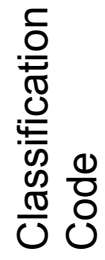 & Red Interval (Effecting Actuation of Red/Green Transition) \\
\hline R1 & $\begin{array}{l}\text { Failure to Actuate Correctly (Fail) - During red interval, first vehicle not } \\
\text { detected within five seconds of arrival or, after initial detection, logical OR of } \\
\text { detection zones for all waiting vehicles FALSE at any time prior to observed } \\
\text { R/G transition. }\end{array}$ \\
\hline R2 & $\begin{array}{l}\text { False actuation (False) - During red interval, when no vehicles are present in } \\
\text { any detection zone, detection occurs, either continuous or intermittent. }\end{array}$ \\
\hline & Green Interval (Effecting Actuation of Green/Red Transition) \\
\hline G1 & $\begin{array}{l}\text { Potential failure to extend green - During green interval, one or more vehicle(s) } \\
\text { or platoons(s) was not detected. }\end{array}$ \\
\hline G2 & $\begin{array}{l}\text { Potentially false green extension - During green interval, detection occurred } \\
\text { when no vehicle or vehicles was/were present. }\end{array}$ \\
\hline
\end{tabular}

Table 4-6: Phase Actuation Error Descriptions 


\section{CHAPTER 5. DISCUSSION OF RESULTS}

\subsection{Video Missed Calls / Loop False Calls in Through-Right Lanes (Table 4-1)}

On the eastbound approach, the right turn lane is configured with a large radius so that vehicles begin their turn prior to the stop bar and subsequently aim their headlights away from the video detection. Additionally, drivers tend to pull very far forward of the stop bar during the red phase as they search for a gap in traffic on the perpendicular roadway. Due to these two characteristics of the approach, there are many instances of the very rear of a vehicle being on the loop detection zone, but the headlights of the vehicle or the entire vehicle itself being outside of the video detection zone. These discrepancies occurred during both the May and September tests and almost exclusively at night, when the only visible portion of the vehicle is the headlights and hence the only portion that is sensed by the video detection units. During the day, these discrepancies did not occur because video detection units can detect the rear of vehicles. During the May test, the missed call during night by the video detector due to the headlights being outside of the video detection zone was the most common type of missed call on all three systems. This illustrates how video detection zones may change unintentionally at night due to the system not being able to sense the rear part of the vehicle, which is not visible at night at non-illuminated intersections. The second type of L1V0 discrepancy was caused by pure misses by the video detection, that is when a vehicle and a vehicle's headlights are within the detection zone and no call is placed. During the May test all of these types of errors on the through phase resulted after an initial call was placed but then dropped by the video detection unit. For missed calls of this type greater than 5 seconds in length, the Autoscope unit did not miss any calls, the Peek unit had 15 missed calls and the Iteris unit had 3 missed calls. During the September 
test, the Peek system missed 82 calls completely and dropped 12 calls, mostly during the nighttime hours. In addition, the Iteris system missed 11 calls completely and dropped 56 calls. The Autoscope system missed 1 call completely and dropped 2 calls.

The loop detector placed one false call during the May test on the through phase, after a vehicle departed the detection zone, the loop remained activated for approximately 8 seconds after the vehicle departure. No false calls were observed by the loop detector during the September test.

\subsection{Video Missed Calls / Loop False Calls in Left-Turn Lane (Table 4-1)}

The video detector units did not have a large number of missed calls on the left-turn lane, compared to the through-right movement.

During the May test, the Autoscope system had 6 missed calls in the leftturn lane. Two were from a vehicle initially being sensed but then the call being dropped; in one of these cases the vehicle was eventually sensed again. One of the errors was caused by a dark colored vehicle who was not initially sensed but was eventually picked up by the video detector. Another error was caused by a phenomenon of a large vehicle (usually a class 9 truck) crossing on the perpendicular roadway and obscuring the detection zone long enough for the video detection to drop the call. This type of error has been nicknamed the "Truck Wipe" error. The last two errors were caused by vehicles slowly creeping into the detection zone and therefore causing the video detection to activate at least 5 seconds after the loop. During the September test, 2 errors were cause by the dark colored vehicle, one error was caused by the "Truck Wipe," and one error was caused by a vehicle stopping with its headlights in front of the stopbar, thereby missing the video detection zone.

During the May test, the Peek system had 6 missed calls in the left-turn lane. Four of the six errors occurred at night when the vehicle was in the detection zone and the headlights were at or just past the stop bar causing the 
video detection to drop the vehicle call. The other two missed calls were caused by a "Truck Wipe" as described under the Autoscope system. In fact, one of the errors occurred at exactly the same time as the error on the Autoscope system. During the September test, the Peek system missed 20 calls. Four of the twenty missed calls were due to a vehicle stopping with its headlights in front of the stop bar at night. The remaining 16 errors were not attributable to any obvious cause on the video. Thirteen of the sixteen errors were complete misses. The remaining three errors were dropped calls after detection.

During the May test, the Iteris system did not have any missed calls in the left-turn lane. During the September test, the Iteris system missed 6 calls. Two were due to headlights in front of the stop bar, two were due to the "Truck Wipe" error, and two were unexplained.

The loop detector did not place any false calls during either the May or September test.

\subsection{Video False Calls / Loop Missed Calls in Through-Right Lanes (Table 4-3a} and Table 4-3b)

During the May test, the Autoscope system showed the most false calls in the through-right lanes. Overall, 30 false calls were recorded over the 24-hour test period. They occurred for no explainable reason (such as shadows or occlusion). The detector would either place a call when no vehicles were in the detection zone or it would hold a call after all vehicles had left the detection zone. Twenty-five false calls were attributed to the video detector latching after detecting a vehicle. In addition, 5 false calls resulted in a latched condition. During the September test, the Autoscope system logged 33 unexplained false calls, and 17 due to latching. Also, one false call latched.

During the May test, the Peek system had 14 false calls in the throughright lanes over the 24-hour test period. Seven of the false calls occurred after all vehicles had left the detection zone and yet a call was maintained (latched), and 
7 were unexplained. During the September test, the Peek system logged 21 false calls for unexplained reasons.

During the May test, the Iteris system had 6 false calls in the through-right lanes. Three of the false calls occurred when the system activated even though there were no vehicles in the detection zone and no vehicles had just departed the detection zone. The other three false calls were apparently caused by the Iteris camera activating early due to headlights reflecting off of the pavement. During the September test, 65 false calls were placed by the Iteris system. Twenty-six of these calls were due to the system activating early due to headlights. The remaining 39 were due to the detector latching after a vehicle left the detection zone. Also during the September test, one false call latched.

During the May test, the loop had one missed call, however it was caused when a vehicle in the right turning lane decided to go to the through lane at the last moment and wound up parking on the painted triangle between the right-turn lane and through lane. There are no loops at that point, however all three cameras maintained the call. The loop had no missed calls during the September test.

\subsection{Video False Calls / Loop Missed Calls in Left-Turn Lane (Table 4-3a and}

Table 4-3b)

During the September test, the Autoscope system had the tendency to extend calls after a left-turning vehicle had moved past the stop bar into the middle of the intersection while waiting for a gap in the opposing traffic stream. These false calls may be eliminated with a more judicious placement of the video detection zone; as they accounted for 39 of the 61 false calls. The other 22 false calls genuinely occurred as an error. On seven of the 41 false calls, there was a large vehicle in the through lane which may have caused a false call to be placed in the left-turn lane. For four of the remaining false calls, there was no obvious cause for the error. Eleven were due to latching after a vehicle left the detection 
zone. Twenty-three false calls resulted in a latched call. During the September test, the Autoscope also logged the most false calls. Twenty-three of the 109 false calls were due to the detection of a left turning vehicle past the stop bar. Sixty of the remaining false calls were due to a shadow or occlusion from the adjoining through lane. Four false calls were due to the detector latching after a vehicle left the detection zone. The remaining 22 false calls were not attributable to any obvious cause. Twenty-five false calls resulted in a latch.

During the May test, the Peek system also demonstrated a large number of false calls on the left-turn phase. The Peek system had 52 false calls in the left-turn lane over the 24-hour test period. Fourteen of these false calls were due to occlusion from a large vehicle in the through lanes, activating a false call in the left-turn lane. Two of the false calls were caused by vehicles who had left the stop-bar and were waiting in the middle of the intersection for a gap in the opposing traffic stream. Eleven false calls were due to the video detector latching after a vehicle left the detection zone. The remaining 25 false calls occurred with no obvious explanation as to the cause. Fourteen false calls resulted in a latch. During the September test, the Peek system logged 96 false calls. Three false calls were due to the system detecting a left turning vehicle after it had passed the stop bar, 62 were due to an occlusion or shadow from the adjoining through lane, 15 were due to a latched call, and the remaining 16 were unexplained. Nineteen false calls resulted in a latch.

During the May test, the Iteris system fared the best with respect to false calls in the left-turn lane. There were 10 false calls during the 24-hour test period, and 7 of the false calls occurred when vehicles crept past the stop-bar waiting for a gap in adjacent traffic. Some of these types of discrepancies could likely be eliminated with an adjustment to the video detection zone. One false call was due to a detection that latched. The remaining two false calls occurred without reason and lasted a long duration, in both cases greater than 90 seconds. Two false calls resulted in a latch. The Iteris system also had the fewest number of false calls in the left turn lane during the September test, though this time it logged 45 false calls. Five of the calls were due to the detection of a left turning 
vehicle past the stop bar, 5 were attributed to an occlusion or shadow from the adjacent through lane, 2 was due to early activation of the system because of headlights, 7 were unexplained, and the remaining 27 false calls were due to a latched call. Nine false calls resulted in a latch.

There were no missed calls observed from the loop detectors during either the May or September test periods.

\subsection{Detector Error Impacts on Signal Operations (Table 4-5)}

The impact that a missed or false call has on the signal operation varies depending on when the error occurs. A false call during the red interval can cause a large amount of delay for vehicles on the cross street as green time is used to serve vehicles that aren't there. A false call during the green phase would extend the green unnecessarily, also causing delay for cross traffic. A missed call during either the red or green interval can lead to safety issues. As was discussed earlier, missed calls during the red can lead to a driver running the red interval, and a missed call during the green interval can place vehicles in the dilemma zone. Table 4-5 lists the tabulation of those impacts, while Table 4-6 describes the classification of the impact on signal operations by the missed and false calls, 


\section{CHAPTER 6. CONCLUSIONS}

In each of the tests completed, each of the three video detection systems displayed a number of false calls and missed calls. In comparison the loop detectors were remarkably accurate producing only one missed call and one false call over the 48 hour duration of the tests. The missed call was a result of a vehicle making a last second decision to proceed through the intersection, as opposed to turning right. Because of this, the vehicle spent the red interval parked in the hashed area between the right turn lane and the through lane, where there is no loop detection. The false call was a result of the loop detector sticking on for approximately 8 seconds after the departure of a vehicle.

Both false calls and missed calls can negatively impact the operation of an actuated traffic signal. Due to the high number of false and missed calls produced by video detection, it should be expected that traffic signals with this type of detection technology will operate less efficiently and less safely than a traffic signal with a more accurate detection technology such as inductive loops.

In both tests, the Econolite Autoscope video detection system demonstrated a relatively low number of missed calls (14 and 23 Missed Calls). However, this was at the sacrifice of producing the most false calls in both tests (110 and 159 False Calls). This system is the most conservative, and tends to error on the side of placing a call rather than potentially missing a vehicle.

The Peek system had the most missed calls of the three systems during both tests (46 and 147 Missed Calls). By looking at activation histograms, it appears that the Peek system was less susceptible to the headlight effect, which is the tendency for video detection systems to activate early at night due to headlight reflections on the pavement. 
Finally, the Iteris system showed very good performance in the first test by producing a relatively low number of missed calls (9 Missed Calls) and false calls (15 False Calls). However, in the second test the operation of the system degraded significantly producing a high number of both missed calls (99 Missed Calls) and false calls (110 False Calls).

One of the most troubling trends between the first and second tests, was the apparent degradation of performance of the video detection systems over time. The number of missed calls and false calls increased across all three systems in both tests. Each of the systems was calibrated prior to the May 2005 test, but was not re-calibrated prior to the September 2005 test. The Peek camera was fitted with an infrared device between the two tests. There were no identifiable factors in the second test that would have caused such degradation in performance across the three video detectors other than that over time they must be re-calibrated to maintain their performance.

In summary:

- Each video detection system showed a moderate to high number of missed and false calls over the two test periods. The loop detector showed only 1 missed call and 1 false call over both 48 hour test periods.

- The Econolite Autoscope unit was the most likely to place a false call, however it displayed the lowest number of missed calls.

- The Peek system's performance degraded between the two tests even with the installation of an infrared unit on the camera. Peek was the least susceptible to the "headlight effect".

- The Iteris system had the best performance in the first test, but degraded significantly with the second test.

- None of the three systems appeared to provide superior performance over the other three. The most accurate and reliable technology was the traditional loop detectors. 
- The accuracy of all three systems appears to degrade with time and it appeared that a re-calibration was necessary only 4 months after the initial installation by factory representatives. 


\section{LIST OF REFERENCES}

1. Ginsberg, S. "Traffic-Light Timing System Only Leaves Drivers Idling: Vaunted Cameras Along Route 7 on the Blink." Washington Post, November 6, 2005, natl. ed.: Page C04.

2. MacCarley, C. A., S. L. M. Hockaday, D. Need, and S. Taff. Evaluation of Video Image Processing Systems for Traffic Detection. In Transportation Research Record: Journal of the Transportation Research Board, No. 1360, TRB, National Research Council, Washington, D.C. 1992.

3. Minnesota Department of Transportation - Minnesota Guidestar and SRF Consulting Group. Field Test of Monitoring of Urban Vehicle Operations Using Non-Intrusive Technologies, Volume 5, Task Three Report: Extended Field Test Results, Minnesota Guidestar, St. Paul, Minnesota, and SRF Consulting Group, Minneapolis, Minnesota, 1996.

4. Middleton, D. and R. Parker. Initial Evaluation of Selected Detectors to Replace Inductive Loops on Freeways. Publication FHWA/TX-03/2119-1. Texas Transportation Institute, Texas Department of Transportation, FHWA, 2002.

5. Grenard, J., D. Bullock, and A. P. Tarko. Evaluation of Selected Video Detection Systems at Signalized Intersections. Publication FHWA/IN/JTRP-2001/22. Joint Transportation Research Program, Indiana Department of Transportation, Purdue University, 2001.

6. Rhodes A., D. Bullock, J. Sturdevant, Z. Clark, and D. Candey. Evaluation of Stop Bar Video Detection Accuracy at Signalized Intersections. Transportation Research Board (\#05-0384), TRB, National Research Council, Washington, D.C. 2005. 
7. MacCarley, C. A., and J. Palen. Evaluation of Video Traffic Sensors for Intersection Signal Actuation: Methods and Metrics. Transportation Research Board, National Research Council, Washington, D.C., 2003. 